\title{
Yeast as a Model System to Study Tau Biology
}

\author{
Ann De Vos, Jayamani Anandhakumar, Jeff Van den Brande, Mathias Verduyckt, \\ Vanessa Franssens, Joris Winderickx, and Erwin Swinnen
}

Laboratory of Functional Biology, Catholic University of Leuven, Kasteelpark Arenberg 31, 3001 Heverlee, Belgium

Correspondence should be addressed to Erwin Swinnen, erwin.swinnen@bio.kuleuven.be

Received 7 December 2010; Accepted 21 January 2011

Academic Editor: Jeff Kuret

Copyright () 2011 Ann De Vos et al. This is an open access article distributed under the Creative Commons Attribution License, which permits unrestricted use, distribution, and reproduction in any medium, provided the original work is properly cited.

Hyperphosphorylated and aggregated human protein tau constitutes a hallmark of a multitude of neurodegenerative diseases called tauopathies, exemplified by Alzheimer's disease. In spite of an enormous amount of research performed on tau biology, several crucial questions concerning the mechanisms of tau toxicity remain unanswered. In this paper we will highlight some of the processes involved in tau biology and pathology, focusing on tau phosphorylation and the interplay with oxidative stress. In addition, we will introduce the development of a human tau-expressing yeast model, and discuss some crucial results obtained in this model, highlighting its potential in the elucidation of cellular processes leading to tau toxicity.

\section{Introduction}

Alzheimer's disease (AD) is the most common age-related neurodegenerative disorder, clinically manifested by a progression from episodic memory problems to a slow global decline of cognitive function that leaves patients with endstage $\mathrm{AD}$ bedridden and dependent on custodial care, with death occurring on average 9 years after diagnosis [1]. The two distinctive key hallmarks of $\mathrm{AD}$ consist of senile plaques (SP), composed of extracellular deposits of amyloid$\beta$ peptides $(\mathrm{A} \beta)$, and intracellular neurofibrillary tangles (NFT), formed by accumulation of abnormal filaments of protein tau, in brain regions that serve memory and cognition [2, 3]. Although numerous studies have been performed on both $\mathrm{A} \beta$ and tau biology, the exact molecular mechanisms behind the pathology are still not completely elucidated. Current therapies used to treat $\mathrm{AD}$ patients are aimed to ameliorate symptoms for a limited period. At this point, there is no approved treatment with a proven diseasemodifying effect $[1,4]$.

Early studies mainly focused on the $\mathrm{A} \beta$ biology, in part because several genetic mutations leading to early onset familial AD were identified in the genes encoding the $\beta$-amyloid precursor protein (APP) and presenilins, components of the $\gamma$-secretase complex, which are involved in the formation of $\mathrm{A} \beta$ peptides [5]. Over the past decade, however, tau biology has received increasing attention. In 1998, for instance, it was demonstrated that mutations in tau were responsible for another neurodegenerative disease, frontotemporal dementia and Parkinsonism linked to chromosome 17 (FTDP-17) [6-8]. These mutations unequivocally proved that tau malfunctioning, in itself, can result in neurodegeneration and cognitive decline. In addition, tau is implicated in neurodegeneration in various other diseases, such as Pick's disease and progressive supranuclear palsy (PSP), which, similar to AD and FTDP-17, are all characterized by the appearance of intraneuronal inclusions of aggregated tau proteins [9-11]. All the diseases marked by an abnormal tau pathology are collectively annotated as "tauopathies" and strongly suggest that tau malfunction is a major factor underlying neurodegeneration in all these diseases. In this respect, many studies concerning AD have indicated an intimate link between $\mathrm{A} \beta$ and tau pathology, whereby $\mathrm{A} \beta$ accumulation would constitute an upstream event, triggering tau pathology and neurodegeneration [12, 13]. Indeed, amyloid deposition was demonstrated to precede tau tangle formation in a triple transgenic mouse model of Alzheimer's disease [14]. Furthermore, administration of $\mathrm{A} \beta_{42}$, the most fibrillogenic form of $\mathrm{A} \beta$ peptide, has been shown to induce the formation of tau-containing filaments, both in tissue culture [15], as in P301L transgenic mice [16]. Importantly, tau has also been shown to be essential 
for $A \beta$-induced toxicity. In cultured hippocampal neurons, tau knockout resulted in the loss of neurodegeneration in the presence of $A \beta$ [17]. In addition, reducing endogenous tau was shown to ameliorate $\mathrm{A} \beta$-induced behavioral deficits in an $\mathrm{AD}$ mouse model, without altering their high $\mathrm{A} \beta$ levels [18]. Thus, all these data indicate that, while $A \beta$ accumulation may represent the prime trigger in the onset of $\mathrm{AD}$, tau pathology likely constitutes the crucial effector of neurodegeneration in this disease. Key questions that remain to be solved involve the molecular nature of the toxic tau species as well as the molecular mechanisms leading to neurodegeneration.

\section{Tau: Physiological Functions}

Tau, also known as microtubule associated protein tau (MAPT), is predominantly expressed in neurons where its main function seems to be the stabilization of microtubules (MTs), particularly in axons. The MAPT gene is located on chromosome 17 and consists of 16 exons $[19,20]$. In the central nervous system, alternative splicing of exons 2 , 3 , and 10 yields six tau isoforms (Figure 1). The isoforms differ by the presence or absence of one or two acidic inserts at the N-terminal domain, and whether they contain three or four repeats of a conserved tubulin binding motif at the C-terminal. The tubulin-binding repeat region is the central part of the microtubule-binding domain (MTBD), and tau isoforms with 4 repeats (4R-Tau) bind microtubules with greater affinity than isoforms with three repeats (3R$\mathrm{Tau}$ ). In normal adult human tissue, the ratio of $4 \mathrm{R}-$ to $3 \mathrm{R}-\mathrm{Tau}$ is $\sim 1[21,22]$. The MT-binding affinity of tau is posttranslationally regulated primarily by serine/threonine directed phosphorylation, which can effectively modulate the binding affinity of tau for MTs [23]. Through its ability to modulate MT dynamics, tau plays a vital role in regulating the appropriate morphology of neurons. In addition, as the MT network is key to the sophisticated transport machinery allowing for transport of molecules and organelles (e.g., mitochondria and vesicles) along the axons, tau clearly can have profound effects on axonal transport and, hence, on the function and viability of neurons and their highly extended processes [24]. Under normal physiological conditions, tau is in a constant dynamic equilibrium, on and off the MTs. As MT-binding of tau is largely controlled by its phosphorylation status, cellular morphology and axonal transport are critically dependent on the balance of the activities of tau kinases and phosphatases.

Interestingly, although the primary function of tau appears to be the stabilization of microtubules, it has been shown that tau can also interact, either directly or indirectly, with actin and affect actin polymerization as well as the interaction of actin filaments with microtubules [26-31]. Furthermore, tau interacts with the plasma membrane and with several proteins involved in signal transduction, in most part via its $\mathrm{N}$-terminal projection domain [32-39]. The binding of tau to signalling molecules implies that tau is either a downstream substrate or a regulator of the activity of the proteins it binds, or even both. For instance, tau is not only phosphorylated by the Fyn kinase $[40,41]$, it also
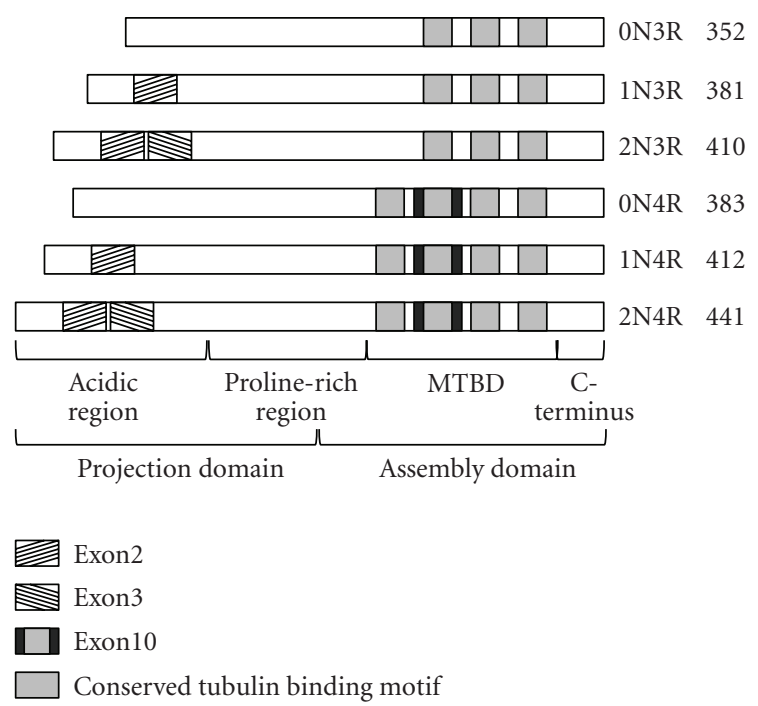

Figure 1: Schematic representation of the six isoforms of tau, present in the central nervous system, and their amino acid lengths. The isoforms are generated by alternative splicing of exons 2, 3, and 10. As shown for the longest isoforms (2N4R), tau can be divided into the projection domain and the assembly domain, based on the cleavage by chymotrypsin after Tyr197 [25]. While tau binds to MT via the microtubule-binding domain (MTBD) in the assembly domain, sequences in the projection domain regulate, among others, the spacing between MT. In an alternative description, tau is subdivided into 4 domains: an $\mathrm{N}$-terminal acidic region, followed by the proline-rich region, the MTBD, and the C-terminal tail.

modulates Fyn activity [42]. Interestingly, Fyn is shown to play a crucial role in the recruitment of both $\mathrm{A} \beta$ and tau into lipid rafts $[43,44]$. The importance of these interactions of tau with proteins and structures other than the actin and microtubule cytoskeleton is largely unknown, especially in the context of tau-mediated neurodegeneration. Still, these findings support the notion that tau is prone to a large number of heterogeneous interactions, and irregularities of some of these interactions may lead, or contribute, to protein misfolding and aggregation, and even cell death through, as yet, unknown mechanisms.

\section{Tau Pathology}

As mentioned above, the progressive accumulation of NFT, composed of insoluble, hyperphosphorylated tau in a filamentous form, is a common hallmark of all tauopathies, including $\mathrm{AD}$. As the severity of dementia in $\mathrm{AD}$ was shown to correlate well with NFT load, in contrast to SP load [4547], these aggregated forms of tau were, at first, thought to be the prime toxic component. However, this concept is still under debate, as several lines of evidence indicate that the tau aggregates are not major toxic components, and may even represent a protective mechanism, by which the neuronal cell attempts to detoxify other harmful species of tau by sequestering them into relatively inert aggregates $[10,48]$. Indeed, tau-mediated neuronal death, in the absence of tau filaments, is observed in Drosophila and some 
transgenic mouse models overexpressing human tau [4951]. In addition, mouse models of tauopathies exist, in which a dissociation was found between tangle formation in some areas distinct from neuronal loss in others $[52,53]$. Finally, in the transgenic mouse model $\mathrm{rTg} 4510$, conditionally expressing the human tau P301L mutant, age-related NFT develop, along with neuronal loss and memory impairment. Yet, subsequent suppression of the mutant tau was shown to stabilize neuronal loss and improve memory function, even though NFT continue to accumulate [54]. Further detailed analysis of tau pathology in this mouse model suggested that the accumulation of early-stage aggregated tau species, including hyperphosphorylated multimers of tau, and not the end-stage NFT, are correlated with the development of cognitive deficits during the pathogenic progression of tauopathy [55]. Thus, these studies suggest that tau-mediated neuronal death does not require the formation of NFT. Rather, nonfilamentous tau, in a more soluble, hyperphosphorylated, and possibly oligomeric state, may represent the prime neurotoxic tau component.

Apart from the exact nature of the toxic tau species, additional controversy surrounds the question of the molecular mechanisms mediating cell death. Regarding this issue, it is becoming increasingly evident that tau-mediated neurodegeneration may encompass multiple mechanisms, including both loss of normal functions and toxic gains-offunctions acquired by the aggregates and their precursors (Figure 2).

Tau pathology might arise from several cytoskeletonmediated defects. Since the major physiological function ascribed to tau is the regulation of MT dynamics, tau malfunction has been reported to induce a loss of MT stability [56-58] and hamper proper axonal transport [59-63]. Impairment of these cellular functions initiates synaptic damage, an early event observed in multiple tauopathies [6468], ultimately leading to neurodegeneration. In addition, tau may also mediate neurotoxicity, at least in part, by altering the organization and dynamics of the actin cytoskeleton [27].

Through its ability to interact with the plasma membrane and to bind a variety of proteins, tau is proposed to participate in cell signalling [32-38]. Therefore, abnormal alterations in the phosphorylation of tau, and possibly other abnormal tau modifications, may aberrantly affect its association with the plasma membrane and with various signaling molecules, possibly leading to a toxic outcome. In this respect, a model for the molecular events leading to neurodegeneration in $\mathrm{AD}$ was recently proposed, connecting amyloid and tau dysfunction to a Fyn-dependent, NMDA receptor-mediated excitotoxicity [69-72]. Although several aspects of this model need further confirmation, it accounts for the tau-dependency of $\mathrm{A} \beta$-induced toxicity $[17,18]$, as well as the observed requirement of activation of NMDA receptors to induce cell death by tau overexpression in cultured neurons [69].

Aside from phosphorylation, proteolytic processing of tau constitutes another intensely studied posttranslational modification [25]. Truncation of tau may generate amyloidogenic tau fragments that initiate the aggregation of tau and/or result in tau fragments which induce neurodegeneration through unknown mechanisms, independently of tau aggregation. Caspase-mediated tau cleavage is an early event in the $\mathrm{AD}$ progression [73]. Although caspases are known to play essential roles in apoptosis, the involvement of the latter process in the mediation of tau-induced cell death is still obscure, as both proapoptotic and antiapoptotic features of tau are described in the literature [74-76]. Recently, in vivo imaging techniques in the transgenic rTg4510 mouse model revealed a dissociation between caspase activation and acute neuronal death in tangle-bearing neurons [77]. Therefore, these authors suggested that neurons undergo a slow, nonapoptotic but caspase-associated form of cell death in tauopathy, in which caspase cleavage of tau seeds an aggregate that actually sequesters toxic tau species. Although this process delays cell death, it results in a sick neuron that loses connections and eventually dies. Aside from the well-known involvement of caspases in tau processing, the proteasome is also shown to degrade tau [78, 79], though hyperphosphorylated tau seems resistant to this proteasomemediated clearance $[13,80]$. Interestingly, tau aggregates have been reported to inhibit proteasome activity [81], correlating with the decreased activity of the proteasome in AD-affected brain $[82,83]$.

As illustrated by all the studies mentioned above, tau dysfunction likely contributes to neurodegeneration via multiple mechanisms, acting at different stages of disease. Still, the exact nature of toxic tau species remains unknown, as is the sequence of events leading to tau-mediated cell death. Indeed, although correlations are quite easy to observe, it is more difficult to discern which is cause, and which is consequence. In addition, it is still unclear which aspects of aging, the greatest risk factor of all for disease development, are involved in the onset of tau pathology, and to what extent. Aging is known to affect a plethora of processes, such as glucose and insulin metabolism, inflammation, oxidative stress management, and the protein quality control system. For most of them, the molecular mechanisms connecting these processes to tau pathology are still largely elusive $[25,88-91]$. The general trend, however, is that there seems to be a bidirectional relation between these processes and tau pathology, because defects in these processes seem to induce tau hyperphosphorylation and aggregation and, on the other hand, tau pathology results, for instance, in increased oxidative stress and inflammation. Thus, a picture emerges in which, when cellular stress surpasses a certain threshold level, tau toxicity is induced and a seemingly unstoppable self-sustaining cycle is created, propagating the disease throughout the brain. Further elucidating the causes of tau malfunction may provide new insights into the initiating factors of tau pathology and first toxic tau intermediates. This information will be of great value in the development of new therapeutic strategies combating tau pathologies. We will now briefly review cellular aspects involved in tau phosphorylation and oxidative stress, two important determinants of tau pathology, since, as we will discuss further below, we recapitulated elements of these features in our humanized yeast system. 


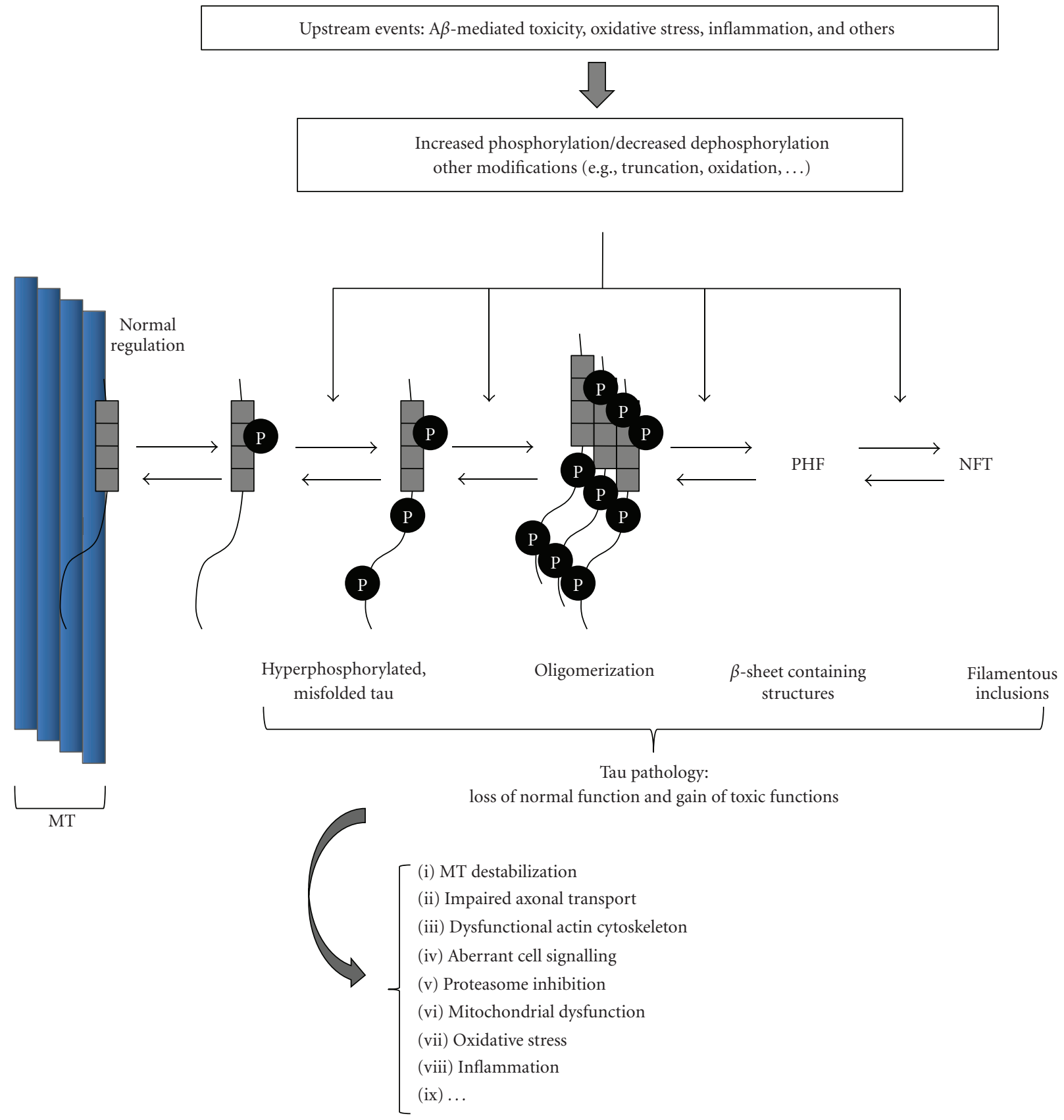

FIgURE 2: Chain-of-events involved in the onset and propagation of tau pathology. Several upstream events have been shown to lead to tau malfunctioning, such as $\mathrm{A} \beta$-mediated effects in Alzheimer's disease. Tau hyperphosphorylation and truncations are thought to constitute early and crucial modifications involved in tau pathology, and may mediate conformational changes leading to oligomerization and aggregation into higher-order aggregates, such as paired-helical filaments (PHF) and end-stage neurofibrillary tangles (NFT). Different forms or tau, especially hyperphosphorylated, oligomeric species, are thought to mediate toxicity via multiple mechanisms, including both loss of normal functions and gain of toxic functions. Note that some consequences of tau toxicity, such as stimulation of oxidative stress and neuroinflammation, reinforce further tau malfunctioning, creating a detrimental, self-sustaining cycle that propagates tau pathology throughout the brain. See text for details.

3.1. Regulation of the Phosphorylation Status of Tau. The phosphorylation of tau plays a physiological role in regulating the affinity of tau for MT. In addition, tau in AD, and other tauopathies, is characterized by an abnormally hyperphosphorylated state. As the phosphorylation state of tau is controlled by the activities of various tau kinases and phosphatases, these enzymes, and their regulators, have received much attention for their role in tauopathies.

Two groups of kinases have been implicated in tau phosphorylation: proline-directed protein kinases (PDPKs) and non-PDPKs. The PDPKs include glycogen synthase kinase $3 \beta$ (Gsk-3ß), cyclin-dependent protein kinase 5 
(Cdk5), mitogen-activated protein kinase, and several stressactivated protein kinases (SAPK). Gsk- $3 \beta$ and Cdk5 are the two best characterized in vivo tau kinases [92]. Both kinases copurify with MT [93-95], and phosphorylate tau within a cellular environment [96-98]. Data from in vitro studies indicate that phosphorylation of tau by Gsk-3 $\beta$ inhibits its ability to promote MT assembly $[99,100]$. Intriguingly, Gsk$3 \beta$ pseudophosphorylated mutants of tau not only displayed a decreased affinity for MT, but also reduced inducerinitiated rates of nucleation and polymerization in vitro, indicating that phosphorylation of tau by Gsk- $3 \beta$ might not per se lead to increased tau aggregation [101]. Multiple lines of evidence indicate that Gsk-3 $\beta$ is a key player affecting tau toxicity in vivo. For instance, the cotransfection of tau with Gsk-3 $\beta$ in a cell culture model results in more cell death compared to the expression of tau and mutant (inactive) Gsk-3 $\beta$, suggesting that tau phosphorylation by Gsk-3 $\beta$ is toxic [102]. In addition, inhibition of Gsk3 by lithium not only reduced tau phosphorylation in vivo, but also lowered the level of aggregated tau, compared with controls [103]. Like Gsk-3 $\beta$, Cdk5 is intensively investigated for its role in the development of tau pathology. Tau is a proven Cdk5 target in vivo [92] and in vitro, it was shown that phosphorylation by $\mathrm{Cdk} 5$ promotes tau dimerization [104]. Activation of Cdk5, by overexpressing its activator p25, accelerates tau phosphorylation and aggregation in mice overexpressing mutant P301L tau [105], and has even been shown to contribute to tau pathology in mice expressing only endogenous tau [106, 107]. Of interest, Cdk5 activity is elevated in the prefrontal cortex of $\mathrm{AD}$ brain, where NFT are found, but not in the cerebellar cortex, suggesting a relationship between deregulated Cdk5 activity and tau pathology in humans $[108,109]$. Although Cdk5 is shown to phosphorylate tau directly [92], there are reports that Cdk5 activity also affects the tau phosphorylation status indirectly $[110,111]$, which, under certain conditions, may occur via a Cdk5-mediated inhibition of Gsk-3 $\beta$ activity [112]. Among the tau non-PDPKs are cyclic AMP-dependent protein kinase (PKA), calcium- and calmodulin-dependent protein kinase II (CaMKII), and microtubule affinity regulating kinase (MARK). MARK phosphorylates tau at KXGS motifs within the MTBD of tau, thereby inducing the release of tau from MT $[113,114]$. Interestingly, in an in vitro study, it was shown that phosphorylation of tau by MARK and PKA led to a strongly reduced affinity of tau for MT, along with a decrease of tau's ability to assemble into paired helical filaments [114]. Although at first glance this may contradict the correlation of hyperphosphorylated tau with the occurrence of NFT in tauopathies, this result is in agreement with the hypothesis that not the NFT, but soluble hyperphosphorylated forms of tau represent the toxic species as discussed above. Unbound tau, generated by MARK and/or PKA phosphorylation, may subsequently be phosphorylated by other kinases, generating the notorious "hyperphosphorylated" tau. In fact, the phosphorylation of tau by MARK may be a prerequisite for the action of downstream kinases, including Gsk-3 $\beta$ and Cdk5 [115].

Obviously, the phosphorylation state of tau is dictated not only by kinase activity, but also by the activities of tau phosphatases. Tau is dephosphorylated by protein phosphatases $2 \mathrm{~A}(\mathrm{PP} 2 \mathrm{~A})$ and, to a lesser extent, by PP1, PP2B, and PP5 [37, 116-118]. In $\mathrm{AD}$ brain, it is found that the mRNA and protein expression levels of some of these phosphatases, as well as their activities, are decreased [118124]. Therefore, downregulation of phosphatase activity, especially that of PP2A, can contribute to increased levels of hyperphosphorylated tau. In addition, Pin1, a member of the peptidyl-prolyl cis-trans isomerases, is involved in the regulation of the phosphorylation state of tau, as Pin1 binds tau when it is phosphorylated at Thr231 and facilitates its dephosphorylation by PP2A [39, 125-127]. Notably, Pin 1 is significantly downregulated and oxidized in the AD hippocampus [128]. Furthermore, in AD neurons, Pin 1 binds hyperphosphorylated tau in filaments, potentially depleting soluble Pin1 levels [39, 129].

As hyperphosphorylation of tau constitutes an early modification, inducing further conformational changes and aggregation of tau, modulation of the activities of tau kinases and phosphatases represents an appealing strategy to combat tau pathologies. Major focus has been on modulation of important tau kinases, especially Gsk-3 $\beta[103,130]$, though no successful outcome has yet been reported for clinical trials using Gsk-3 $\beta$ inhibitors, such as lithium and valproic acid [4].

3.2. Oxidative Stress and Tau Pathology. Accumulating evidence suggests that, besides the accumulation of protein aggregates, oxidative stress and mitochondrial dysfunction, which are intimately linked, also play an important role in the etiology of neurodegenerative diseases, including $\mathrm{AD}$ $[89,90]$. As mitochondria are a major source of reactive oxygen species (ROS), malfunctions of these organelles are thought to be a prime contributor to cellular oxidative stress. Additionally, mitochondrial dysfunction will lead to decreased energy production, which puts an extra burden on neurons, which are heavily dependent on high ATP levels to sustain many biochemical processes, especially involving neurotransmission at their synapses. Numerous reports are available demonstrating direct $\mathrm{A} \beta$-mediated impairment of mitochondrial function [91]. In contrast, the link between tau and mitochondrial function is still more elusive. Still, a proteomic and functional analysis showed a mitochondrial dysfunction in P301L mice, together with reduced NADHubiquinone oxidoreductase activity, and, with age, impaired mitochondrial respiration and ATP synthesis [131]. In the aged transgenic mice, mitochondrial dysfunction was associated with higher levels of ROS, and increased tau pathology revealed modified lipid peroxidation levels and the upregulation of antioxidant enzymes in response to oxidative stress. Interestingly, as the P301L mice displayed an increased vulnerability towards $A \beta$ insult, this suggests that $\mathrm{A} \beta$ and tau pathology work synergistically on mitochondria, through distinct mechanisms [132]. Although a direct impact of tau on some mitochondrial proteins/enzymes is hypothesized, this remains to be confirmed. In another study, the addition of annonacin, a natural mitochondrial complex I inhibitor, caused a redistribution of tau from the 
axons to the cell body, along with a retrograde transport of mitochondria and cell death [133]. Retrograde transport of dysfunctional mitochondria is a general feature, priming them for elimination by autophagy [134-136]. Interestingly, although annonacin addition caused an increase in oxidative stress, ATP depletion was shown to be the primary trigger for tau relocalization, mitochondrial retrograde transport, and cell death [133]. Thus, although tau pathology seems to induce mitochondrial dysfunction, leading to increased ROS, the concurrent decreased ATP levels must not be overlooked, as both these signals can play vital roles in neuronal survival.

Oxidative stress in AD and other neurodegenerative diseases has also been linked to increased brain levels of certain metals, especially iron $(\mathrm{Fe})$, copper $(\mathrm{Cu})$, and zinc $(\mathrm{Zn})$ [137139]. Both $\mathrm{Fe}$ and $\mathrm{Cu}$ are capable of inducing oxidative stress by stimulating free radical formation (e.g., hydroxyl radicals via Fenton reaction). In $\mathrm{AD}, \mathrm{Fe}$ - and $\mathrm{Cu}$-induced oxidative reactions are accelerated by $\mathrm{A} \beta$, and $\mathrm{A} \beta$ oligomerization is stimulated in the presence of these metals. Interestingly, it was recently shown that the APP protein functions as an iron-export ferroxidase, whose activity is inhibited by $\mathrm{Zn}$ [140]. As $\mathrm{Zn}$ is locally concentrated in $\mathrm{A} \beta$-plaques [141], this will lead to excessive Fe retention in APP expressing neurons, creating a self-sustaining cycle, wherein increased Fe retention induces further $\mathrm{A} \beta$-oligomerization and plaque formation, further inhibiting $\mathrm{Fe}$ export. In regards to tau biology, metals may influence the self-assembly of tau, as low micromolar concentrations of $\mathrm{Zn}$ have been shown to accelerate the fibrillization of human tau via the bridging of two cysteine residues under physiological reducing conditions [142]. Under oxidizing conditions, however, intermolecular disulfide cross-linking of tau can occur, facilitating its oligomerization [143]. Furthermore, similar to A $\beta$ plaques, NFT were found to be capable of adventitious binding of $\mathrm{Cu}$ and $\mathrm{Fe}$ in a redox-competent manner, indicating that NFT may exert prooxidant or antioxidant activities, depending on the balance among cellular reductants and oxidants in the local environment [144, 145].

Finally, oxidative stress not only results in directly damaging modifications of cell constituents, ROS also function as signalling molecules, affecting the activity of several kinases and phosphatases. Surprisingly, oxidative stress by addition of hydrogen peroxide resulted in a dephosphorylation of tau [146]. Subsequent studies indicated that, on one hand, oxidative stress induces a Pin1-mediated activation of protein phosphatase 2A [125]. On the other hand, an increased activity of protein phosphatase 1 (PP1) was observed, due to a Cdk5-mediated inhibition of inhibitor-2, a negative regulator of PP1 [111]. Thus, although Cdk5 is generally considered as a bona fide in vivo tau kinase, these and other results indicate that this kinase can influence the phosphorylation state of tau in multiple, antagonizing ways [92, 110-112]. Intriguingly, in $\mathrm{AD}$ brain, oxidative stress is observed, though tau is found in a hyperphosphorylated state, in contrast to the observed oxidative stress-induced dephosphorylation of tau described above. In this respect, it was found that oxidative stress combined with okadaic acid, which inhibits both PP1 and PP2A, results in a hyperphosphorylated tau species which was significantly resistant to degradation [80].
These data suggest that, in tauopathies, a combination of oxidative stress and hyperphosphorylation may be directly responsible for the accumulation of tau aggregates.

Considering the fact that oxidative stress constitutes a hallmark of numerous neurodegenerative diseases, strategies that ameliorate this stress are studied intensively as possible therapeutic treatments. Several approaches have been postulated, targeting different aspects of oxidative stress. These include the supplementation with antioxidants or a mixture of antioxidants (e.g., vitamin C and E) [138], the use of specific mitochondria-targeted antioxidants [90], and the modulation of metal bioavailability [139, 147]. Promising initial results of some of these strategies have been described, and outcomes of clinical trials are heavily anticipated.

\section{A Humanized Yeast Model to Study Tau Biology}

The basic cellular machinery and molecular processes between the budding yeast Saccharomyces cerevisiae and other eukaryotic species, including humans, appears to be highly conserved. Consequently, as many yeast genes have functional orthologues in mammalian organisms, yeast has been an effective model system for the study of diverse cellular processes, including mechanisms involved in glucose response [148], apoptosis [149], and cancer [150]. In addition, so-called "humanized" yeast systems have been constructed to study disease-related proteins that have no, or no apparent, functional yeast orthologue, such as the human tau protein. These humanized yeast systems have also proven to be valuable tools to unravel disease-related molecular processes and to identify novel medicinal compounds [151]. Examples of this type of studies in the field of neurodegenerative disorders include protein-misfolding disorders such as Alzheimer's, Parkinson's, and Huntington's disease $[152,153]$.

In our laboratory, we expressed different isoforms and clinical FTDP-17 mutant forms of tau in yeast, and found that tau exhibits many of the same features as it does in neurons of patients with $\mathrm{AD}$, that is, hyperphosphorylation, conformational changes, and partial accumulation into aggregates [84-86]. We will now go over our most important findings on the impact of phosphorylation as well as oxidative stress on tau properties in our yeast model.

4.1. Phosphorylation of Tau in Yeast and Its Consequences. Phosphorylation of tau in mammalian cells controls its interactions with MT while its hyperphosphorylation is thought to cause, or contribute to, the aggregation and toxicity of this protein. In order to assess tau phosphorylation in yeast, we employed a series of phosphospecific tau antibodies to scan phosphorylated residues on tau. We found that tau, when expressed in yeast, became reactive to a multitude of these antibodies, proving the existence of yeast kinases and/or phosphatases able to recognize and (de)phosphorylate human protein tau (Figure 3) [84]. In addition, we could detect tau with the conformationdependent antibody MC1, a marker for pathological tau 


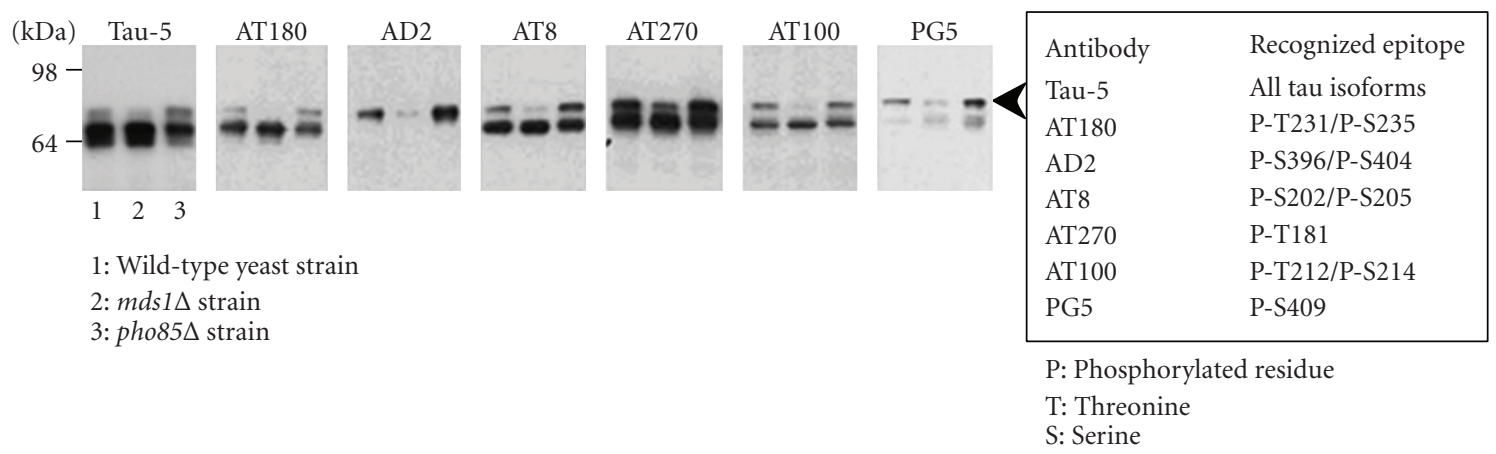

FIGURE 3: Phosphoepitope mapping of human protein tau (2N4R isoform) in yeast. Western blotting with indicated monoclonal antibodies of total protein extracts from wild-type (lanes 1), $m d s 1 \Delta$ (lanes 2), and pho85 (lanes 3) yeast strains. The arrowhead on the right denotes a slow-mobility, hyperphosphorylated tau species. Adapted from [84] with permission from the publisher and the authors.

filaments and their precursors [154-156], and demonstrate a reproducible amount of tau present in the sarkosyl-insoluble fraction ( $\operatorname{Sin} \mathrm{T}$, sarkosyl-insoluble tau), pointing to tau aggregation in yeast [84].

To study the role of yeast kinases in the phosphorylation and aggregation of tau, we set out to test the involvement in tau phosphorylation of Mds1 and Pho85, functional yeast orthologues of mammalian Gsk-3 $\beta$ and Cdk 5 , respectively. Deletion of MDS1 led to a significant decrease in tau's immunoreactivity to both AD2 and PG5. For the AD2 epitope (P-S396/P-S404), this was expected, as it constitutes a typical Gsk-3 $\beta$ target [50, 157, 158]. Phosphorylation of tau at S409 (PG5 epitope), however, is not a typical substrate of Gsk-3 $\beta$, but of PKA, indicating that Mds1 might affect phosphorylation at this site indirectly $[159,160]$. Interestingly, deletion of $\mathrm{PHO} 55$ resulted in a hyperphosphorylation of tau, mainly at the AD2 and PG5 epitopes [84]. This hyperphosphorylation was accompanied by an increase in MC1-reactive tau species and increased SinT levels, compared to control levels. It thus appears that Pho85 does not phosphorylate tau directly in yeast. This may not be so strange, as, also in mammalian cells, evidence exists that Cdk5 has indirect effects on the phosphorylation status in tau, exemplified by the study of Hallows et al., also demonstrating an increase in tau phosphorylation upon Cdk5 inactivation, by knockout of its activating partner p35 [110]. Since deletion of MDS1 and PHO85 both affect the AD2 and PG5 epitopes in opposite ways [84], it is tempting to speculate that Pho85 exerts its effects on tau by inhibiting Mds1. Although this has not yet been proven in yeast, we demonstrated, by means of yeast epistasis analysis combined with complementation studies using the human Gsk-3 $\beta$ and Cdk5 kinases, that Mds1/Gsk-3 $\beta$ genetically operates downstream of Pho85/Cdk5 in the phosphorylation of tau in our yeast system [86]. Intriguingly, studies in a mouse model also imply that Cdk5 might inhibit Gsk-3 $\beta$ activity under certain conditions [112].

Additional data on the physiological consequences of tau phosphorylation in a yeast environment were obtained via two separate in vitro tests, for which tau was purified from wild-type (WT), $m d s 1 \Delta$, and pho85 $\Delta$ yeast strains using an anion exchange chromatography method [84, 85].
We could confirm that, after purification, tau retained its phosphorylation status, characteristic for each strain. In a first assay, we observed that the in vitro tau filament formation was much faster when using tau isolated from the pho85 $\Delta$ strain, compared to tau extracted from either a WT and $m d s 1 \Delta$ yeast strain, consistent with the hyperphosphorylated state of tau in a pho85 strain [84]. In addition, further fractionation of tau extracts yielded a hyperphosphorylated, MC1-reactive subfraction, and we demonstrated that this species could vastly accelerate the in vitro aggregation of tau extracted from a WT strain, implicating a seeding capacity of this hyperphosphorylated tau species. In a second series experiments, we investigated the in vitro MT binding capacity of purified tau, using taxolstabilized MT formed with pig tubulin [85]. In this assay, we could demonstrate an inverse relation between MT binding and tau phosphorylation status, as hyperphosphorylated tau, isolated from pho85 $\Delta$ cells, showed the poorest MT binding, followed by tau extracted from a WT strain, and finally tau extracted from the $m d s 1 \Delta$ strain, which showed impaired phosphorylation.

To gain further insight into the relation between tau phosphorylation and aggregation in our yeast system, several clinical FTDP-17 mutants were expressed in WT, $m d s 1 \Delta$, and pho $85 \Delta$ yeast strains, and their phosphorylation patterns and SinT levels were analyzed [86]. Most notably, compared to wild-type tau, both the P301L and R406W mutants displayed a clear reduction in the phosphorylation of S409 (PG5 epitope) and decreased SinT levels, particularly in a pho85 $\Delta$ strain. These findings suggested that phosphorylation of tau at S409 might be an important determinant for tau aggregation. To confirm this hypothesis, we mutagenized the PG5 epitope and expressed the synthetic tau-S409A mutant and its pseudophosphorylated counterpart tau-S409E in WT and pho85 strains. Analysis of these synthetic mutants indeed revealed a marked decrease of tau-S409A aggregation while the tau-S409E mutant displayed SinT levels higher than, or comparable to, wild-type tau (Figure 4). Interestingly, we demonstrated that phosphorylation of S409 is also detrimental for tau-MT interaction [85], revealing a close, antagonistic link between the ability of tau to bind MT and its ability to aggregate. Intriguingly, the tau-S409A 

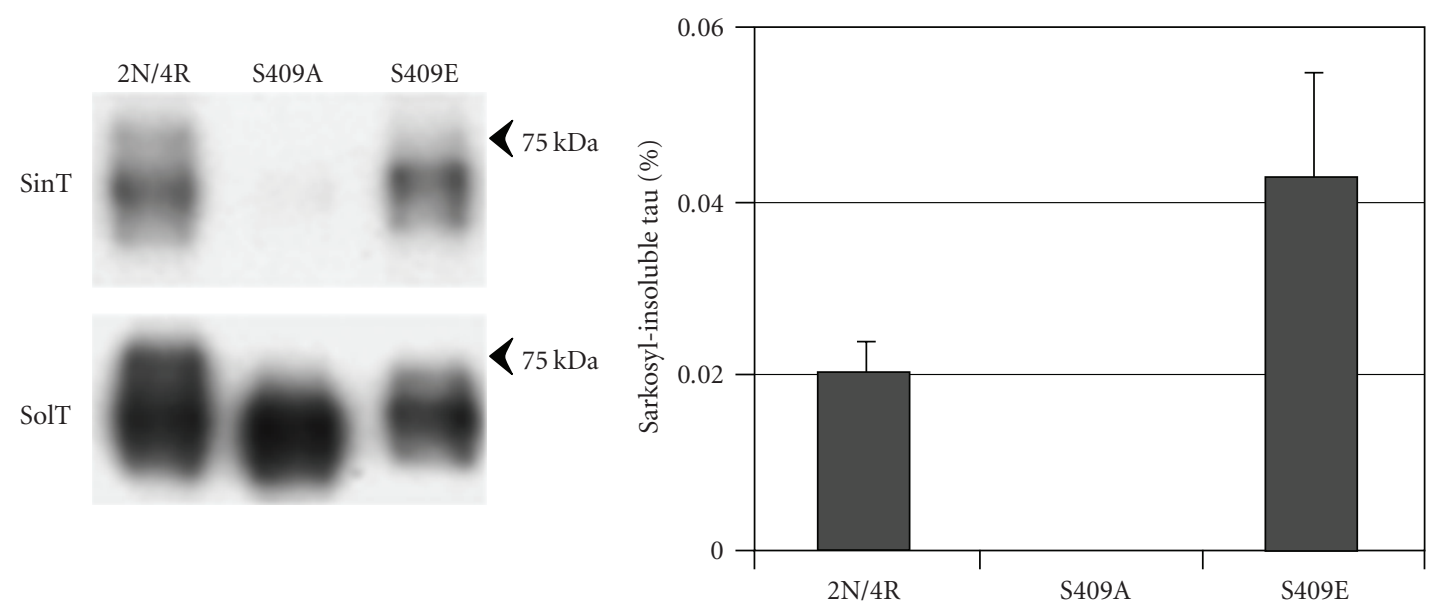

(a)
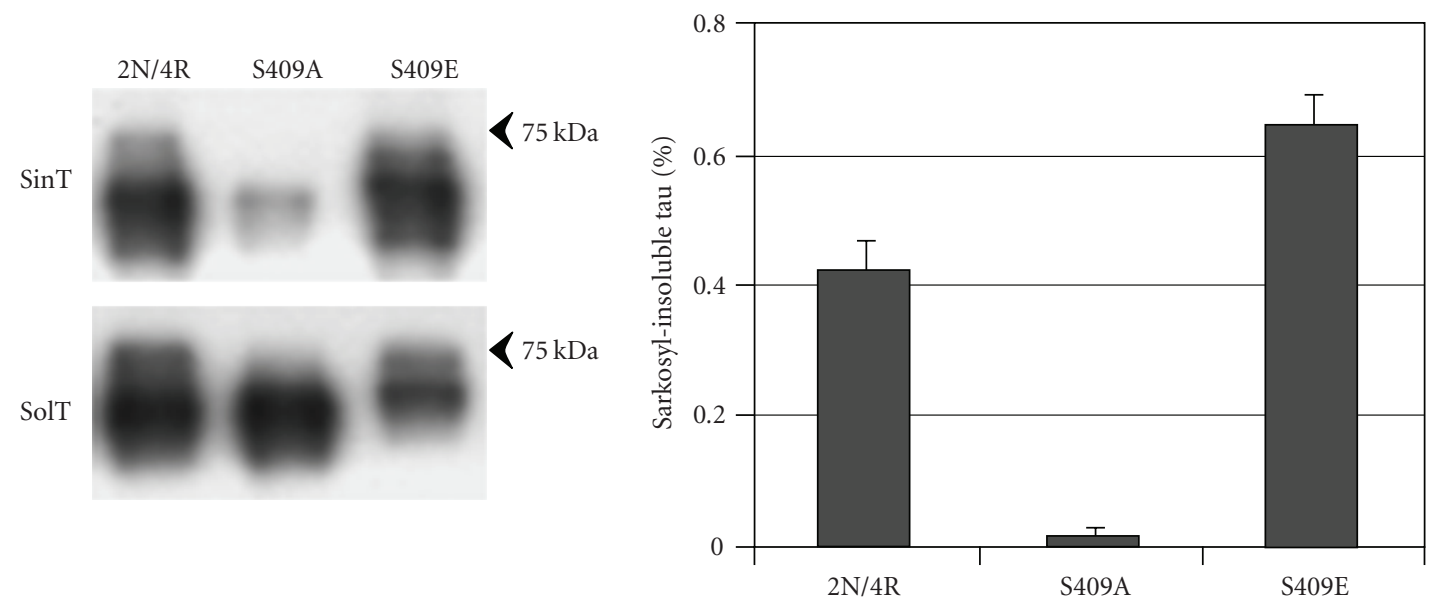

(b)

Figure 4: Determination of soluble (SolT) and sarkosyl-insoluble (SinT) fractions from wild-type tau or the synthetic mutants tau-S409A and tau-S409E, as obtained in WT cells (a) or pho85 $\Delta$ cells. (b) Western blot with tau 5 of a representative experiment is shown on the left, and quantifications of SinT levels for each experiment are shown on the right. Adapted from [86] with permission from the publisher and the authors.

mutant was characterized with a lower AD2 reactivity while the pseudophosphorylated tau-S409E exhibited an increased immunodetection with the AD2 antibody, especially in the WT strain [86]. Thus, phosphorylation of tau at the PG5 and $\mathrm{AD} 2$ epitopes seems interdependent, and phosphorylation of tau at S409 might prime subsequent phosphorylation of S396/S404. These observations are in line with data from the brain of $\mathrm{AD}$ patients, demonstrating that the formation of the PG5 epitope on tau is an early event in the pretangle stage, and precedes the phosphorylation at S396, which is characteristic for NFT [161].

In conclusion of this part, we can say that we have demonstrated that, when expressed in yeast, tau is phosphorylated at multiple pathologically relevant sites. Interestingly, Mds1 and Pho85, the yeast orthologues of human Gsk- $3 \beta$ and Cdk5, respectively, play crucial roles in the phosphorylation of several of these epitopes. Furthermore, our data substantiate the notion that hyperphosphorylation of tau leads to a loss of MT-binding capacity, along with the induction of conformational changes, detectable by the
MC1 antibody, which ultimately lead to tau aggregation $[155,156]$. Finally, we show that phosphorylation of S409 is a crucial mediator in both tau aggregation and MT binding. It is important to emphasize that the tau-MT binding assays described here were performed in vitro using MT built from pig tubulin. We are, as yet, unable to demonstrate binding of tau to yeast MT, likely due to differences in yeast and mammalian tubulins $[162,163]$.

\subsection{In Yeast, Oxidative Stress and Mitochondrial Dysfunction} Enhance Tau Aggregation Independently of Phosphorylation. As discussed previously, evidence exists suggesting a link between oxidative stress and tau pathology. We investigated the effects of oxidative stress and mitochondrial dysfunction on tau aggregation by adding $\mathrm{Fe}^{2+}$, a known inducer of oxidative stress, to yeast cells, or by examining SinT levels in specific mitochondrial mutants, respectively [86]. Interestingly, in both conditions, markedly increased tau insolubility was observed through mechanisms that are not strictly dependent on phosphorylation of tau, but rather 
TABLE 1: Cellular processes involved in tau biology and/or pathology, and their amenability for study in the humanized yeast system. Readers should be aware that this table is not a complete overview of all cellular processes involved in tau biology/pathology and is meant to illustrate some opportunities and limitations of the humanized yeast system. Note the multitude of processes and orthologues, not yet studied in yeast at present.

\begin{tabular}{|c|c|}
\hline $\begin{array}{l}\text { Processes involved in tau } \\
\text { biology/pathology }\end{array}$ & Opportunity for humanized yeast system? \\
\hline $\begin{array}{l}\text { Kinases/phosphatases determining the } \\
\text { phosphorylation status of tau }\end{array}$ & $\begin{array}{l}\text { (i) Multitude of phosphotau species demonstrated in yeast (see Figure } 3 \text { and }[84] \text { ) } \\
\text { (ii) Yeast orthologues of important tau kinases } \\
\text { (1) Gsk-3ß (Mds1) (studied in [84-86]) } \\
\text { (2) Cdk5 (Pho85) (studied in [84-86]) } \\
\text { (3) PKA (Tpk1-3) } \\
\text { (4) CaMKII (Cmk1/Cmk2) } \\
\text { (iii) Yeast orthologues of important tau phosphatases } \\
\text { (1) PP1 (Glc7) } \\
\text { (2) PP2A (Pph21/Pph22, Sit4) } \\
\text { (iv) Yeast orthologue of Pin1 (Ess1) }\end{array}$ \\
\hline Tau mutations & $\begin{array}{l}\text { Several clinical FTDP-17 tau mutants have been expressed in yeast, and the effects of their } \\
\text { mutation on tau phosphorylation and aggregation have been investigated [86] }\end{array}$ \\
\hline $\begin{array}{l}\text { Effect of oxidative stress and/or } \\
\text { mitochondrial dysfunction on tau } \\
\text { pathology }\end{array}$ & $\begin{array}{l}\text { Both oxidative stress and mitochondrial dysfunction are amenable to yeast studies } \\
\text { (i) } \mathrm{Fe}^{2+} \text {-induced oxidative stress increases tau aggregation (SinT) in yeast [86] } \\
\text { (ii) Tau aggregation (SinT) is increased in mitochondrial mutants sod } 2 \Delta \text { and } \operatorname{rim} 1 \Delta[86]\end{array}$ \\
\hline $\begin{array}{l}\text { Tau binding to } \\
\text { (i) MT } \\
\text { (ii) Actin } \\
\text { (iii) (plasma) membrane }\end{array}$ & $\begin{array}{l}\text { (i) Binding of tau to yeast MT not (yet) demonstrated, although tau purified from yeast } \\
\text { binds to mammalian (pig) MT in vitro }[85,86] \\
\text { (ii) Binding of tau to yeast actin cytoskeleton is not yet investigated } \\
\text { (iii) Binding of tau to yeast plasma membrane or other intracellular membranes is not yet } \\
\text { studied }\end{array}$ \\
\hline $\begin{array}{l}\text { Processes involved in tau clearance } \\
\text { (i) apoptosis/caspase-cleavage of tau } \\
\text { (ii) ubiquitin-proteasome system } \\
\text { (iii) autophagic-lysosomal system }\end{array}$ & $\begin{array}{l}\text { All these processes are present in yeast and can thus be studied for their effects on tau biology } \\
\text { in the humanized yeast system } \\
\text { Note: yeast does not contain true orthologues of mammalian caspases, though it contains a } \\
\text { caspase-related protease Yca1 (termed "meta"caspase), involved in yeast apoptosis [87]. The } \\
\text { cleavage-specificity of caspases (cleave after aspartic acid) is different from that of } \\
\text { metacaspases (cleave after arginine or lysine) }\end{array}$ \\
\hline Aging & $\begin{array}{l}\text { Stationary-phase yeast can serve as a model for aging effects. Not yet studied for effects on tau } \\
\text { biology/pathology in the humanized yeast system }\end{array}$ \\
\hline Aberrant cellular signalling & $\begin{array}{l}\text { As tau has no apparent yeast orthologue, yeast cellular signalling pathways are intrinsically } \\
\text { independent on normal tau functioning. Neuron-specific, tau-dependent signalling pathways } \\
\text { are therefore not amenable for studies in yeast }\end{array}$ \\
\hline Inflammation & $\begin{array}{l}\text { Not applicable for studies in yeast. Though we note that one of the major consequences of } \\
\text { inflammation is the generation of oxidative stress, which can be studied in a yeast } \\
\text { environment }\end{array}$ \\
\hline
\end{tabular}

act mainly in parallel. Close examination of Western blot profiles indicated that oxidative stress led to a reduction in the level of tau dimers, concomitant with an increase in higher-order oligomers. Furthermore, a $35 \mathrm{kDa}$ degradation product appeared after the addition of $\mathrm{Fe}^{2+}$, indicative of altered processing and/or diminished clearance of tau fragments under this condition. Strikingly, application of oxidative stress led to decreased phosphorylation of tau at specific epitopes, especially AD2 and PG5 (Figure 5). This is consistent with several studies in neuronal cells showing a dephosphorylation of tau upon exposure to oxidative stress $[111,125,146]$. Two mechanisms accounting for this oxidative stress-induced tau dephosphorylation have been described, both of which seem to be conserved in yeast. In the first, increased activity of protein phosphatase 1 (PP1) was observed, due to a Cdk5-mediated inhibition of inhibitor-2, a negative regulator of PP1 [111]. Interestingly, the Cdk5/p35 complex is functionally equivalent to the yeast Pho85/Pcl6,7 complex, which phosphorylates Glc8, the orthologue of mammalian inhibitor-2, thereby controlling the activity of the Glc7 phosphatase, the orthologue of mammalian PP1 [164]. In the second mechanism, oxidative stress induced a Pin1-mediated activation of protein phosphatase 2A [125]. Pin 1 function is represented by the yeast orthologue Ess1 [165], and our unpublished results indicate that disruption of Ess1 activity leads to increased hyperphosphorylation of tau. Hence, it appears that similar mechanisms may govern oxidative stress-induced tau dephosphorylation in yeast and mammalian cells, highlighting the value of studying tau biology in yeast.

4.3. Future Perspectives for the Humanized Yeast Model. One important aspect of our research in tau-expressing yeast cells, is that we did not observe strong tau-related growth phenotypes in any of the strains, even under conditions 


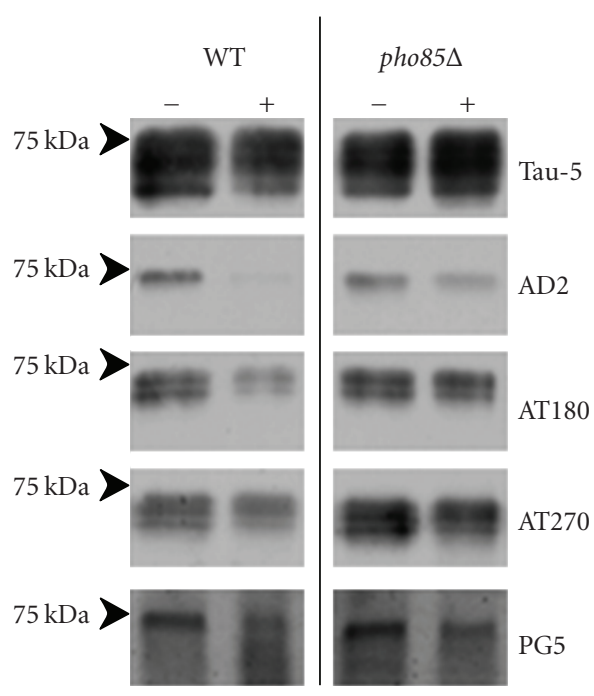

FIGURE 5: Western blot analysis with the indicated antibodies, of total protein extracts isolated from tau-expressing WT and pho85 $\Delta$ cells grown in a medium without $(-)$ or with supplementation of $20 \mathrm{mM} \mathrm{FeSO}_{4}(+)$. See Figure 3 for antibody specificity. Adapted from [86] with permission from the publisher and the authors.

which displayed a strong induction of tau aggregation. This implies that tau aggregation is not per se correlated with toxicity, a conclusion that correlates directly with findings in mammalian systems, in which NFT were found not to be essential for tau-induced toxicity and may even play a protective function $[48,55]$. In addition, all the results discussed here concerning tau phosphorylation and aggregation, were obtained from exponentially growing yeast cells. Since, for instance, mitochondrial activity, a factor believed to be involved in the etiology of tauopathies, is more important during the yeast's stationary phase than during fermentation, investigating the impact of tau on cellular fitness during yeast aging may present us with new clues on tau toxicity.

It is needless to say that we have just started to scratch the surface on studying possible mediators of tau biology and pathology in yeast (see Table 1). In our studies, we focused mainly on the role of Mds1 and Pho85, functional yeast orthologues of mammalian Gsk-3 $\beta$ and Cdk5, respectively, in the phosphorylation of tau in yeast. Obvious candidates for further research include the yeast orthologues of protein phosphatases involved in tau dephosphorylation, such as PP2A and PP1, and of Pin1. As mentioned, our unpublished results already indicate a hyperphosphorylated tau status upon decreased activity of Ess1, the yeast orthologue of Pin1. Interestingly, in contrast to a pho85 strain, we did observe a toxic effect of tau on growth of yeast cells with impaired Ess1 activity. This implies that the toxicity of "hyperphosphorylated" tau is not a general feature, but likely applies to a specific combination of phosphorylated epitopes. Detailed investigation of Ess1-dependent tau modifications is currently in progress. In this regard, it would be of great interest to extend this type of analysis by employing a genome-wide screen for yeast mutants displaying taudependent toxicity. Analysis of the phosphorylation pattern and SinT levels in such mutants can provide crucial new information regarding toxic tau species and molecular players involved in their generation.

As a final note, we mention that, although we did not see a tau-induced toxicity in yeast, we observed synthetic toxicity upon the coexpression of tau with $\alpha$-synuclein [166]. Thus, it seems that tau can exert hazardous effects in yeast, but in the absence of other stressors, this does not reveal itself by a growth defect. Increase of cellular stress, by coexpression of $\alpha$-synuclein, however, apparently results in the exceeding of a certain threshold, thereby revealing a tau-dependent toxicity. Detailed analysis of impaired cellular processes upon coexpression of tau with $\alpha$-synuclein, in conjunction with the above-mentioned genome-wide screening, may thus reveal which cellular machineries are affected by tau overexpression in yeast.

\section{Concluding Remarks}

As the group of seniors in the world's population continues to grow, age-related neurodegenerative disorders, including tauopathies such as Alzheimer's disease, are becoming more prevalent, and pose a serious threat to an already overwhelmed health care system. Despite the vast amount of research already performed, several aspects of tauopathies still await molecular elucidation. Among these are the nature of toxic tau species and the way they influence cell viability. We developed a yeast model expressing human protein tau variants, and demonstrated that this model recapitulates many important aspects implicated in tau pathology, including hyperphosphorylation, conformation, and aggregation. Combined with the ease of genetic manipulations, rapid genome-wide screening methods, and other advantages characteristic of yeast systems, this model may prove its value in the clarification of fundamental cellular processes involved in tau biology and pathology.

\section{Abbreviations}

$\begin{array}{ll}\text { A } \beta: & \text { Amyloid- } \beta \text { peptide } \\ \text { AD: } & \text { Alzheimer's disease } \\ \text { APP: } & \beta \text {-amyloid precursor protein } \\ \text { FTDP-17: } & \text { Frontotemporal dementia with } \\ & \text { Parkinsonism linked to chromosome } 17 \\ \text { MT: } & \text { Microtubule } \\ \text { MTBD: } & \text { Microtubule-binding domain } \\ \text { NFT: } & \text { Neurofibrillary tangles } \\ \text { PDPK: } & \text { Proline-directed protein kinase } \\ \text { PSP: } & \text { Progressive supranuclear palsy } \\ \text { ROS: } & \text { Reactive oxygen species } \\ \text { rTg4510: } & \text { Transgenic mouse model, conditionally } \\ & \text { expressing the human tau P301L mutant } \\ \text { SAPK: } & \text { Stress-activated protein kinase } \\ \text { SinT: } & \text { Sarkosyl-insoluble tau } \\ \text { SP: } & \text { Senile plaques } \\ \text { WT: } & \text { Wild-type. }\end{array}$




\section{Acknowledgments}

The authors would like to thank Professor F. Van Leuven (Experimental Genetics Group-LEGTEGG, KUL, Belgium), and Dr. L. Bueé and Dr. Marie-Christine Galas (INSERM U837 Alzheimer and Tauopathies, Lille, France) for collaborations and constructive discussions. This paper was supported by IWT-Vlaanderen (SBO NEURO-TARGET and Baekeland), the KULeuven Research Fund (KULeuven BOF-IOF), KULeuven R\&D, and the Marie Curie Ph.D. Graduate School NEURAD.

\section{References}

[1] M. Citron, "Alzheimer's disease: strategies for disease modification," Nature Reviews Drug Discovery, vol. 9, no. 5, pp. 387-398, 2010.

[2] C. Ballatore, V. M. Y. Lee, and J. Q. Trojanowski, "Taumediated neurodegeneration in Alzheimer's disease and related disorders," Nature Reviews Neuroscience, vol. 8, no. 9, pp. 663-672, 2007.

[3] F. M. LaFerla, K. N. Green, and S. Oddo, "Intracellular amyloid- $\beta$ in Alzheimer's disease," Nature Reviews Neuroscience, vol. 8, no. 7, pp. 499-509, 2007.

[4] F. Massoud and S. Gauthier, "Update on the pharmacological treatment of Alzheimer's disease," Current Neuropharmacology, vol. 8, no. 1, pp. 69-80, 2010.

[5] B. de Strooper, "Proteases and proteolysis in alzheimer disease: a multifactorial view on the disease process," Physiological Reviews, vol. 90, no. 2, pp. 465-494, 2010.

[6] M. Hutton, C. L. Lendon, P. Rizzu et al., "Association of missense and 5'-splice-site mutations in tau with the inherited dementia FTDP-17," Nature, vol. 393, no. 6686, pp. 702-704, 1998.

[7] P. Poorkaj, T. D. Bird, E. Wijsman et al., "Tau is a candidate gene for chromosome 17 frontotemporal dementia," Annals of Neurology, vol. 43, no. 6, pp. 815-825, 1998.

[8] M. G. Spillantini, J. R. Murrell, M. Goedert, M. R. Farlow, A. Klug, and B. Ghetti, "Mutation in the tau gene in familial multiple system tauopathy with presenile dementia," Proceedings of the National Academy of Sciences of the United States of America, vol. 95, no. 13, pp. 7737-7741, 1998.

[9] E. M. Ingram and M. G. Spillantini, "Tau gene mutations: dissecting the pathogenesis of FTDP-17," Trends in Molecular Medicine, vol. 8, no. 12, pp. 555-562, 2002.

[10] T. L. Spires-Jones, W. H. Stoothoff, A. de Calignon, P. B. Jones, and B. T. Hyman, "Tau pathophysiology in neurodegeneration: a tangled issue," Trends in Neurosciences, vol. 32, no. 3, pp. 150-159, 2009.

[11] A. C. Ludolph, J. Kassubek, B. G. Landwehrmeyer et al., "Tauopathies with parkinsonism: clinical spectrum, neuropathologic basis, biological markers, and treatment options," European Journal of Neurology, vol. 16, no. 3, pp. 297-309, 2009.

[12] J. Hardy and D. J. Selkoe, "The amyloid hypothesis of Alzheimer's disease: progress and problems on the road to therapeutics," Science, vol. 297, no. 5580, pp. 353-356, 2002.

[13] S. Oddo, L. Billings, J. P. Kesslak, D. H. Cribbs, and F. M. LaFerla, "A $\beta$ immunotherapy leads to clearance of early, but not late, hyperphosphorylated tau aggregates via the proteasome," Neuron, vol. 43, no. 3, pp. 321-332, 2004.

[14] S. Oddo, A. Caccamo, M. Kitazawa, B. P. Tseng, and F. M. LaFerla, "Amyloid deposition precedes tangle formation in a triple transgenic model of Alzheimer's disease," Neurobiology of Aging, vol. 24, no. 8, pp. 1063-1070, 2003.

[15] A. Ferrari, F. Hoerndli, T. Baechi, R. M. Nitsch, and J. Götz, " $\beta$-amyloid induces paired helical filament-like tau filaments in tissue culture," Journal of Biological Chemistry, vol. 278, no. 41, pp. 40162-40168, 2003.

[16] J. Gotz, F. Chen, J. van Dorpe, and R. M. Nitsch, "Formation of neurofibrillary tangles in P301L tau transgenic mice induced by A $\beta 42$ fibrils," Science, vol. 293, no. 5534, pp. 1491-1495, 2001.

[17] M. Rapoport, H. N. Dawson, L. I. Binder, M. P. Vitek, and A. Ferreira, "Tau is essential to $\beta$-amyloid-induced neurotoxicity," Proceedings of the National Academy of Sciences of the United States of America, vol. 99, no. 9, pp. 6364-6369, 2002.

[18] E. D. Roberson, K. Scearce-Levie, J. J. Palop et al., "Reducing endogenous tau ameliorates amyloid $\beta$-induced deficits in an Alzheimer's disease mouse model," Science, vol. 316, no. 5825, pp. 750-754, 2007.

[19] A. Andreadis, W. M. Brown, and K. S. Kosik, "Structure and novel exons of the human $\tau$ gene," Biochemistry, vol. 31, no. 43, pp. 10626-10633, 1992.

[20] R. L. Neve, P. Harris, K. S. Kosik, D. M. Kurnit, and T. A. Donlon, "Identification of cDNA clones for the human microtubule-associated protein tau and chromosomal localization of the genes for tau and microtubule-associated protein 2," Brain Research, vol. 387, no. 3, pp. 271-280, 1986.

[21] M. Goedert and R. Jakes, "Expression of separate isoforms of human tau protein: correlation with the tau pattern in brain and effects on tubulin polymerization," EMBO Journal, vol. 9, no. 13, pp. 4225-4230, 1990.

[22] M. Hong, V. Zhukareva, V. Vogelsberg-Ragaglia et al., "Mutation-specific functional impairments in distinct tau isoforms of hereditary FTDP-17," Science, vol. 282, no. 5395, pp. 1914-1917, 1998.

[23] T. F. Gendron and L. Petrucelli, "The role of tau in neurodegeneration," Molecular Neurodegeneration, vol. 4, no. 1, article 13, 2009.

[24] S. Roy, B. Zhang, V. M. Y. Lee, and J. Q. Trojanowski, "Axonal transport defects: a common theme in neurodegenerative diseases," Acta Neuropathologica, vol. 109, no. 1, pp. 5-13, 2005.

[25] Y. Wang, S. Garg, E. M. Mandelkow, and E. Mandelkow, "Proteolytic processing of tau," Biochemical Society Transactions, vol. 38, no. 4, pp. 955-961, 2010.

[26] H. J. He, X. S. Wang, R. Pan, D. L. Wang, M. N. Liu, and R. Q. He, "The proline-rich domain of tau plays a role in interactions with actin," BMC Cell Biology, vol. 10, article 81, 2009.

[27] G. Gallo, “Tau is actin up in Alzheimer's disease," Nature Cell Biology, vol. 9, no. 2, pp. 133-134, 2007.

[28] T. A. Fulga, I. Elson-Schwab, V. Khurana et al., "Abnormal bundling and accumulation of F-actin mediates tau-induced neuronal degeneration in vivo," Nature Cell Biology, vol. 9, no. 2, pp. 139-148, 2007.

[29] J. Z. Yu and M. M. Rasenick, "Tau associates with actin in differentiating PC12 cells," FASEB Journal, vol. 20, no. 9, pp. 1452-1461, 2006.

[30] G. A. Farias, J. P. Munoz, J. Garrido, and R. B. Maccioni, "Tubulin, actin, and tau protein interactions and the study of their macromolecular assemblies," Journal of Cellular Biochemistry, vol. 85, no. 2, pp. 315-324, 2002.

[31] J. F. Zmuda and R. J. Rivas, "Actin disruption alters the localization of tau in the growth cones of cerebellar granule 
neurons," Journal of Cell Science, vol. 113, no. 15, pp. 27972809, 2000.

[32] A. Agarwal-Mawal, H. Y. Qureshi, P. W. Cafferty et al., "143-3 connects glycogen synthase kinase- $3 \beta$ to tau within a brain microtubule-associated tau phosphorylation complex," Journal of Biological Chemistry, vol. 278, no. 15, pp. 1272212728, 2003.

[33] S. M. Jenkins and G. V. W. Johnson, "Tau complexes with phospholipase C- $\gamma$ in situ," NeuroReport, vol. 9, no. 1, pp. 6771, 1998.

[34] G. Lee, S. Todd Newman, D. L. Gard, H. Band, and G. Panchamoorthy, "Tau interacts with src-family non-receptor tyrosine kinases," Journal of Cell Science, vol. 111, no. 21, pp. 3167-3177, 1998.

[35] H. Liao, Y. Li, D. L. Brautigan, and G. G. Gundersen, "Protein phosphatase 1 is targeted to microtubules by the microtubule- associated protein tau," Journal of Biological Chemistry, vol. 273, no. 34, pp. 21901-21908, 1998.

[36] C. H. Reynolds, C. J. Garwood, S. Wray et al., "Phosphorylation regulates tau interactions with Src homology 3 domains of phosphatidylinositol 3-kinase, phospholipase C $\gamma 1$, Grb2, and Src family kinases," Journal of Biological Chemistry, vol. 283, no. 26, pp. 18177-18186, 2008.

[37] E. Sontag, V. Nunbhakdi-Craig, G. Lee, G. S. Bloom, and M. C. Mumby, "Regulation of the phosphorylation state and microtubule-binding activity of tau by protein phosphatase 2A," Neuron, vol. 17, no. 6, pp. 1201-1207, 1996.

[38] I. E. Vega, E. E. Traverso, Y. Ferrer-Acosta et al., "A novel calcium-binding protein is associated with tau proteins in tauopathy," Journal of Neurochemistry, vol. 106, no. 1, pp. 96106, 2008.

[39] P. J. Lu, G. Wulf, X. Z. Zhou, P. Davies, and K. P. Lu, “The prolyl isomerase Pin1 restores the function of Alzheimerassociated phosphorylated tau protein," Nature, vol. 399, no. 6738, pp. 784-788, 1999.

[40] K. Bhaskar, S. H. Yen, and G. Lee, "Disease-related modifications in tau affect the interaction between Fyn and tau," Journal of Biological Chemistry, vol. 280, no. 42, pp. 3511935125, 2005.

[41] G. Lee, R. Thangavel, V. M. Sharma et al., "Phosphorylation of Tau by Fyn: implications for Alzheimer's disease," Journal of Neuroscience, vol. 24, no. 9, pp. 2304-2312, 2004.

[42] V. M. Sharma, J. M. Litersky, K. Bhaskar, and G. Lee, "Tau impacts on growth-factor-stimulated actin remodeling," Journal of Cell Science, vol. 120, no. 5, pp. 748-757, 2007.

[43] T. Kawarabayashi, M. Shoji, L. H. Younkin et al., "Dimeric amyloid beta protein rapidly accumulates in lipid rafts followed by apolipoprotein $\mathrm{E}$ and phosphorylated tau accumulation in the Tg2576 mouse model of Alzheimer's disease," Journal of Neuroscience, vol. 24, no. 15, pp. 38013809, 2004.

[44] R. Williamson, A. Usardi, D. P. Hanger, and B. H. Anderton, "Membrane-bound $\beta$-amyloid oligomers are recruited into lipid rafts by a fyn-dependent mechanism," FASEB Journal, vol. 22 , no. 5, pp. 1552-1559, 2008.

[45] P. V. Arriagada, J. H. Growdon, E. T. Hedley-Whyte, and B. T. Hyman, "Neurofibrillary tangles but not senile plaques parallel duration and severity of Alzheimer's disease," Neurology, vol. 42, no. 3, pp. 631-639, 1992.

[46] P. Giannakopoulos, F. R. Herrmann, T. Bussiere et al., "Tangle and neuron numbers, but not amyloid load, predict cognitive status in Alzheimer's disease," Neurology, vol. 60, no. 9, pp. 1495-1500, 2003.
[47] T. Gomez-Isla, R. Hollister, H. West et al., "Neuronal loss correlates with but exceeds neurofibrillary tangles in Alzheimer's disease," Annals of Neurology, vol. 41, no. 1, pp. 17-24, 1997.

[48] A. Bretteville and E. Planel, "Tau aggregates: toxic, inert, or protective species?" Journal of Alzheimer's Disease, vol. 14, no. 4, pp. 431-436, 2008.

[49] A. Probst, J. Götz, K. H. Wiederhold et al., "Axonopathy and amyotrophy in mice transgenic for human four-repeat tau protein," Acta Neuropathologica, vol. 99, no. 5, pp. 469-481, 2000.

[50] K. Spittaels, C. van den Haute, J. van Dorpe et al., "Prominent axonopathy in the brain and spinal cord of transgenic mice overexpressing four-repeat human tau protein," American Journal of Pathology, vol. 155, no. 6, pp. 2153-2165, 1999.

[51] C. W. Wittmann, M. F. Wszolek, J. M. Shulman et al., "Tauopathy in Drosophila: neurodegeneration without neurofibrillary tangles," Science, vol. 293, no. 5530, pp. 711-714, 2001.

[52] C. Andorfer, C. M. Acker, Y. Kress, P. R. Hof, K. Duff, and P. Davies, "Cell-cycle reentry and cell death in transgenic mice expressing nonmutant human tau isoforms," Journal of Neuroscience, vol. 25, no. 22, pp. 5446-5454, 2005.

[53] T. L. Spires, J. D. Orne, K. SantaCruz et al., "Region-specific dissociation of neuronal loss and neurofibrillary pathology in a mouse model of tauopathy," American Journal of Pathology, vol. 168, no. 5, pp. 1598-1607, 2006.

[54] K. Santacruz, J. Lewis, T. Spires et al., "Medicine: Tau suppression in a neurodegenerative mouse model improves memory function," Science, vol. 309, no. 5733, pp. 476-481, 2005.

[55] Z. Berger, H. Roder, A. Hanna et al., "Accumulation of pathological tau species and memory loss in a conditional model of tauopathy," Journal of Neuroscience, vol. 27, no. 14, pp. 3650-3662, 2007.

[56] A. C. Alonso, I. Grundke-Iqbal, and K. Iqbal, "Alzheimer's disease hyperphosphorylated tau sequesters normal tau into tangles of filaments and disassembles microtubules," Nature Medicine, vol. 2, no. 7, pp. 783-787, 1996.

[57] A. D. C. Alonso, T. Zaidi, I. Grundke-Iqbal, and K. Iqbal, "Role of abnormally phosphorylated tau in the breakdown of microtubules in Alzheimer disease," Proceedings of the National Academy of Sciences of the United States of America, vol. 91, no. 12, pp. 5562-5566, 1994.

[58] A. D. C. Alonso, I. Grundke-Iqbal, H. S. Barra, and K. Iqbal, "Abnormal phosphorylation of tau and the mechanism of Alzheimer neurofibrillary degeneration: sequestration of microtubule-associated proteins 1 and 2 and the disassembly of microtubules by the abnormal tau," Proceedings of the National Academy of Sciences of the United States of America, vol. 94, no. 1, pp. 298-303, 1997.

[59] I. Cuchillo-Ibanez, A. Seereeram, H. L. Byers et al., "Phosphorylation of tau regulates its axonal transport by controlling its binding to kinesin," FASEB Journal, vol. 22, no. 9, pp. 3186-3195, 2008.

[60] M. Dubey, P. Chaudhury, H. Kabiru, and T. B. Shea, "Tau inhibits anterograde axonal transport and perturbs stability in growing axonal neurites in part by displacing kinesin cargo: neurofilaments attenuate tau-mediated neurite instability," Cell Motility and the Cytoskeleton, vol. 65, no. 2, pp. 89-99, 2008.

[61] L. M. Ittner, Y. D. Ke, and J. Gotz, "Phosphorylated Tau interacts with c-Jun N-terminal kinase-interacting protein 1 (JIP1) in Alzheimer disease," Journal of Biological Chemistry, vol. 284, no. 31, pp. 20909-20916, 2009. 
[62] K. Stamer, R. Vogel, E. Thies, E. Mandelkow, and E. M. Mandelkow, "Tau blocks traffic of organelles, neurofilaments, and APP vesicles in neurons and enhances oxidative stress," Journal of Cell Biology, vol. 156, no. 6, pp. 1051-1063, 2002.

[63] E. Thies and E. M. Mandelkow, "Missorting of tau in neurons causes degeneration of synapses that can be rescued by the kinase MARK2/Par-1," Journal of Neuroscience, vol. 27, no. 11, pp. 2896-2907, 2007.

[64] E. H. Bigio, M. B. Vono, S. Satumtira et al., "Cortical synapse loss in progressive supranuclear palsy," Journal of Neuropathology and Experimental Neurology, vol. 60, no. 5, pp. 403-410, 2001.

[65] A. Brun, X. Liu, and C. Erikson, "Synapse loss and gliosis in the molecular layer of the cerebral cortex in Alzheimer's disease and in frontal lobe degeneration," Neurodegeneration, vol. 4, no. 2, pp. 171-177, 1995.

[66] C. A. Davies, D. M. A. Mann, P. Q. Sumpter, and P. O. Yates, "A quantitative morphometric analysis of the neuronal and synaptic content of the frontal and temporal cortex in patients with Alzheimer's disease," Journal of the Neurological Sciences, vol. 78, no. 2, pp. 151-164, 1987.

[67] A. M. Lipton, C. Munro Cullum, S. Satumtira et al., "Contribution of asymmetric synapse loss to lateralizing clinical deficits in frontotemporal dementias," Archives of Neurology, vol. 58, no. 8, pp. 1233-1239, 2001.

[68] R. D. Terry, E. Masliah, D. P. Salmon et al., "Physical basis of cognitive alterations in Alzheimer's disease: synapse loss is the major correlate of cognitive impairment," Annals of Neurology, vol. 30, no. 4, pp. 572-580, 1991.

[69] G. Amadoro, M. T. Ciotti, M. Costanzi, V. Cestari, P. Calissano, and N. Canu, "NMDA receptor mediates tauinduced neurotoxicity by calpain and ERK/MAPK activation," Proceedings of the National Academy of Sciences of the United States of America, vol. 103, no. 8, pp. 2892-2897, 2006.

[70] C. Haass and E. Mandelkow, "Fyn-tau-amyloid: a toxic triad," Cell, vol. 142, no. 3, pp. 356-358, 2010.

[71] R. Hashimoto, K. Fujimaki, M. R. Jeong, L. Christ, and D. M. Chuang, "Lithium-induced inhibition of Src tyrosine kinase in rat cerebral cortical neurons: a role in neuroprotection against N-methyl-D-aspartate receptor-mediated excitotoxicity," FEBS Letters, vol. 538, no. 1-3, pp. 145-148, 2003.

[72] L. M. Ittner, Y. D. Ke, F. Delerue et al., "Dendritic function of tau mediates amyloid- $\beta$ toxicity in alzheimer's disease mouse models," Cell, vol. 142, no. 3, pp. 387-397, 2010.

[73] R. A. Rissman, W. W. Poon, M. Blurton-Jones et al., "Caspase-cleavage of tau is an early event in Alzheimer disease tangle pathology," Journal of Clinical Investigation, vol. 114, no. 1, pp. 121-130, 2004.

[74] X. A. Liu, K. Liao, R. Liu et al., "Tau dephosphorylation potentiates apoptosis by mechanisms involving a failed dephosphorylation/activation of Bcl-2," Journal of Alzheimer's Disease, vol. 19, no. 3, pp. 953-962, 2010.

[75] R. M. Ramalho, R. J. S. Viana, R. E. Castro, C. J. Steer, W. C. Low, and C. M. P. Rodrigues, "Apoptosis in transgenic mice expressing the P301L mutated form of human tau," Molecular Medicine, vol. 14, no. 5-6, pp. 309-317, 2008.

[76] H.-H. Wang, H.-L. Li, R. Liu et al., "Tau overexpression inhibits cell apoptosis with the mechanisms involving multiple viability-related factors," Journal of Alzheimer's Disease, vol. 21, no. 1, pp. 167-179, 2010.

[77] T. L. Spires-Jones, A. de Calignon, T. Matsui et al., "In vivo imaging reveals dissociation between caspase activation and acute neuronal death in tangle-bearing neurons," Journal of Neuroscience, vol. 28, no. 4, pp. 862-867, 2008.
[78] D. C. David, R. Layfield, L. Serpell, Y. Narain, M. Goedert, and M. G. Spillantini, "Proteasomal degradation of tau protein," Journal of Neurochemistry, vol. 83, no. 1, pp. 176$185,2002$.

[79] O. Goldbaum, M. Oppermann, M. Handschuh et al., "Proteasome inhibition stabilizes tau inclusions in oligodendroglial cells that occur after treatment with okadaic acid," Journal of Neuroscience, vol. 23, no. 26, pp. 8872-8880, 2003.

[80] D. Poppek, S. Keck, G. Ermak et al., "Phosphorylation inhibits turnover of the tau protein by the proteasome: influence of RCAN1 and oxidative stress," Biochemical Journal, vol. 400, no. 3, pp. 511-520, 2006.

[81] S. Keck, R. Nitsch, T. Grune, and O. Ullrich, "Proteasome inhibition by paired helical filament-tau in brains of patients with Alzheimer's disease," Journal of Neurochemistry, vol. 85, no. 1, pp. 115-122, 2003.

[82] J. N. Keller, K. B. Hanni, and W. R. Markesbery, "Impaired proteasome function in Alzheimer's disease," Journal of Neurochemistry, vol. 75, no. 1, pp. 436-439, 2000.

[83] M. L. Salon, L. Morelli, E. M. Castaño, E. F. Soto, and J. M. Pasquini, "Defective ubiquitination of cerebral proteins in Alzheimer's disease," Journal of Neuroscience Research, vol. 62, no. 2, pp. 302-310, 2000.

[84] T. Vandebroek, T. Vanhelmont, D. Terwel et al., "Identification and isolation of a hyperphosphorylated, conformationally changed intermediate of human protein tau expressed in yeast," Biochemistry, vol. 44, no. 34, pp. 11466-11475, 2005.

[85] T. Vandebroek, D. Terwel, T. Vanhelmont et al., "Microtubule binding and clustering of human Tau-4R and Tau-P301L proteins isolated from yeast deficient in orthologues of glycogen synthase kinase- $3 \beta$ or cdk5," Journal of Biological Chemistry, vol. 281, no. 35, pp. 25388-25397, 2006.

[86] T. Vanhelmont, T. Vandebroek, A. de Vos et al., "Serine-409 phosphorylation and oxidative damage define aggregation of human protein tau in yeast," FEMS Yeast Research, vol. 10, no. 8, pp. 992-1005, 2010.

[87] D. Carmona-Gutierrez, T. Eisenberg, S. Buttner, C. Meisinger, G. Kroemer, and F. Madeo, "Apoptosis in yeast: triggers, pathways, subroutines," Cell Death and Differentiation, vol. 17, no. 5, pp. 763-773, 2010.

[88] R. B. Maccioni, G. Farías, I. Morales, and L. Navarrete, "The revitalized Tau hypothesis on Alzheimer's disease," Archives of Medical Research, vol. 41, no. 3, pp. 226-231, 2010.

[89] V. A. Morais and B. de Strooper, "Mitochondria dysfunction and neurodegenerative disorders: cause or consequence," Journal of Alzheimer's Disease, vol. 20, supplement 2, pp. S255-S263, 2010.

[90] D. A. Patten, M. Germain, M. A. Kelly, and R. S. Slack, "Reactive oxygen species: stuck in the middle of neurodegeneration," Journal of Alzheimer's Disease, vol. 20, supplement 2, pp. S357-S367, 2010.

[91] V. Rhein and A. Eckert, "Effects of Alzheimer's amyloid-beta and tau protein on mitochondrial function-role of glucose metabolism and insulin signalling," Archives of Physiology and Biochemistry, vol. 113, no. 3, pp. 131-141, 2007.

[92] K. Imahori, "The biochemical study on the etiology of Alzheimer's disease," Proceedings of the Japan Academy Series $B$, vol. 86, no. 1, pp. 54-61, 2010.

[93] K. Ishiguro, A. Shiratsuchi, S. Sato et al., "Glycogen synthase kinase $3 \beta$ is identical to tau protein kinase I generating several epitopes of paired helical filaments," FEBS Letters, vol. 325, no. 3, pp. 167-172, 1993.

[94] S. Kobayashi, K. Ishiguro, A. Omori et al., "A cdc2-related kinase PSSALRE/cdk5 is homologous with the $30 \mathrm{kDa}$ 
subunit of tau protein kinase II, a proline-directed protein kinase associated with microtubule," FEBS Letters, vol. 335, no. 2, pp. 171-175, 1993.

[95] D. B. Flaherty, J. P. Soria, H. G. Tomasiewicz, and J. G. Wood, "Phosphorylation of human tau protein by microtubuleassociated kinases: GSK3 $\beta$ and cdk5 are key participants," Journal of Neuroscience Research, vol. 62, no. 3, pp. 463-472, 2000.

[96] G. Michel, M. Mercken, M. Murayama et al., "Characterization of tau phosphorylation in glycogen synthase kinase$3 \beta$ and cyclin dependent kinase- 5 activator (p23) transfected cells," Biochimica et Biophysica Acta, vol. 1380, no. 2, pp. 177182, 1998.

[97] U. Wagner, M. Utton, J. M. Gallo, and C. C. J. Miller, "Cellular phosphorylation of tau by GSK- $3 \beta$ influences tau binding to microtubules and microtubule organisation," Journal of Cell Science, vol. 109, no. 6, pp. 1537-1543, 1996.

[98] S. Lovestone, C. L. Hartley, J. Pearce, and B. H. Anderton, "Phosphorylation of tau by glycogen synthase kinase- $3 \beta$ in intact mammalian cells: the effects on the organization and stability of microtubules," Neuroscience, vol. 73, no. 4, pp. 1145-1157, 1996.

[99] D. B. Evans, K. B. Rank, K. Bhattacharya, D. R. Thomsen, M. E. Gurney, and S. K. Sharma, "Tau phosphorylation at serine 396 and serine 404 by human recombinant tau protein kinase II inhibits tau's ability to promote microtubule assembly," Journal of Biological Chemistry, vol. 275, no. 32, pp. 2497724983, 2000.

[100] M. A. Utton, A. Vandecandelaere, U. Wagner et al., "Phosphorylation of tau by glycogen synthase kinase $3 \beta$ affects the ability of tau to promote microtubule self-assembly," Biochemical Journal, vol. 323, no. 3, pp. 741-747, 1997.

[101] Q. Sun and T. C. Gamblin, "Pseudohyperphosphorylation causing $\mathrm{AD}$-like changes in tau has significant effects on its polymerization," Biochemistry, vol. 48, no. 25, pp. 6002$6011,2009$.

[102] H. Shimura, D. Schwartz, S. P. Gygi, and K. S. Kosik, "CHIP-Hsc70 complex ubiquitinates phosphorylated Tau and enhances cell survival," Journal of Biological Chemistry, vol. 279, no. 6, pp. 4869-4876, 2004.

[103] W. Noble, E. Planel, C. Zehr et al., "Inhibition of glycogen synthase kinase- 3 by lithium correlates with reduced tauopathy and degeneration in vivo," Proceedings of the National Academy of Sciences of the United States of America, vol. 102, no. 19, pp. 6990-6995, 2005.

[104] H. K. Paudel, "Phosphorylation by neuronal cdc2-like protein kinase promotes dimerization of tau protein in vitro," Journal of Biological Chemistry, vol. 272, no. 45, pp. 2832828334, 1997.

[105] W. Noble, V. Olm, K. Takata et al., "Cdk5 is a key factor in tau aggregation and tangle formation in vivo," Neuron, vol. 38, no. 4, pp. 555-565, 2003.

[106] M. K. Ahlijanian, N. X. Barrezueta, R. D. Williams et al., "Hyperphosphorylated tau and neurofilament and cytoskeletal disruptions in mice overexpressing human p25, an activator of cdk5," Proceedings of the National Academy of Sciences of the United States of America, vol. 97, no. 6, pp. 2910-2915, 2000.

[107] F. Bian, R. Nath, G. Sobocinski et al., "Axonopathy, tau abnormalities, and dyskinesia, but no neurofibrillary tangles in p25-transgenic mice," Journal of Comparative Neurology, vol. 446, no. 3, pp. 257-266, 2002.

[108] K. Y. Lee, A. W. Clark, J. L. Rosales, K. Chapman, T. Fung, and R. N. Johnston, "Elevated neuronal Cdc2-like kinase activity in the Alzheimer disease brain," Neuroscience Research, vol. 34, no. 1, pp. 21-29, 1999.

[109] H. C. Tseng, Y. Zhou, Y. Shen, and L. H. Tsai, "A survey of Cdk5 activator p35 and p25 levels in Alzheimer's disease brains," FEBS Letters, vol. 523, no. 1-3, pp. 58-62, 2002.

[110] J. L. Hallows, K. Chen, R. A. DePinho, and I. Vincent, "Decreased cyclin-dependent kinase 5 (cdk5) activity is accompanied by redistribution of cdk5 and cytoskeletal proteins and increased cytoskeletal protein phosphorylation in p35 null mice," Journal of Neuroscience, vol. 23, no. 33, pp. 10633-10644, 2003.

[111] C. A. Zambrano, J. T. Egana, M. T. Nunez, R. B. Maccioni, and C. Gonzalez-Billault, "Oxidative stress promotes $\tau$ dephosphorylation in neuronal cells: the roles of cdk5 and PP1," Free Radical Biology and Medicine, vol. 36, no. 11, pp. 1393-1402, 2004.

[112] Y. Wen, E. Planel, M. Herman et al., "Interplay between cyclin-dependent kinase 5 and glycogen synthase kinase $3 \beta$ mediated by neuregulin signaling leads to differential effects on tau phosphorylation and amyloid precursor protein processing," Journal of Neuroscience, vol. 28, no. 10, pp. 26242632, 2008.

[113] G. Drewes, A. Ebneth, U. Preuss, E. M. Mandelkow, and E. Mandelkow, "MARK, a novel family of protein kinases that phosphorylate microtubule- associated proteins and trigger microtubule disruption," Cell, vol. 89, no. 2, pp. 297-308, 1997.

[114] A. Schneider, J. Biernat, M. von Bergen, E. Mandelkow, and E. M. Mandelkow, "Phosphorylation that detaches tau protein from microtubules (Ser262, Ser214) also protects it against aggregation into Alzheimer paired helical filaments," Biochemistry, vol. 38, no. 12, pp. 3549-3558, 1999.

[115] I. Nishimura, Y. Yang, and B. Lu, "PAR-1 kinase plays an initiator role in a temporally ordered phosphorylation process that confers tau toxicity in Drosophila," Cell, vol. 116, no. 5, pp. 671-682, 2004.

[116] G. Drewes, E. M. Mandelkow, K. Baumann, J. Goris, W. Merlevede, and E. Mandelkow, "Dephosphorylation of tau protein and Alzheimer paired helical filaments by calcineurin and phosphatase-2A," FEBS Letters, vol. 336, no. 3, pp. 425432, 1993.

[117] C. X. Gong, T. Lidsky, J. Wegiel, L. Zuck, I. Grundke-Iqbal, and K. Iqbal, "Phosphorylation of microtubule-associated protein tau is regulated by protein phosphatase $2 \mathrm{~A}$ in mammalian brain. Implications for neurofibrillary degeneration in Alzheimer's disease," Journal of Biological Chemistry, vol. 275, no. 8, pp. 5535-5544, 2000.

[118] F. Liu, I. Grundke-Iqbal, K. Iqbal, and C. X. Gong, "Contributions of protein phosphatases PP1, PP2A, PP2B and PP5 to the regulation of tau phosphorylation," European Journal of Neuroscience, vol. 22, no. 8, pp. 1942-1950, 2005.

[119] C. X. Gong, S. Shaikh, J. Z. Wang, T. Zaidi, I. GrundkeIqbal, and K. Iqbal, "Phosphatase activity toward abnormally phosphorylated $\tau$ : decrease in Alzheimer disease brain," Journal of Neurochemistry, vol. 65, no. 2, pp. 732-738, 1995.

[120] Q. Lian, C. J. Ladner, D. Magnuson, and J. M. Lee, "Selective changes of calcineurin (protein phosphatase $2 \mathrm{~B}$ ) activity in Alzheimer's disease cerebral cortex," Experimental Neurology, vol. 167, no. 1, pp. 158-165, 2001.

[121] J. F. Loring, X. Wen, J. M. Lee, J. Seilhamer, and R. Somogyi, "A gene expression profile of Alzheimer's disease," DNA and Cell Biology, vol. 20, no. 11, pp. 683-695, 2001.

[122] E. Sontag, C. Hladik, L. Montgomery et al., "Downregulation of protein phosphatase 2A carboxyl methylation 
and methyltransferase may contribute to Alzheimer disease pathogenesis," Journal of Neuropathology and Experimental Neurology, vol. 63, no. 10, pp. 1080-1091, 2004.

[123] E. Sontag, A. Luangpirom, C. Hladik et al., "Altered expression levels of the protein phosphatase $2 \mathrm{~A} A B \alpha C$ enzyme are associated with Alzheimer disease pathology," Journal of Neuropathology and Experimental Neurology, vol. 63, no. 4, pp. 287-301, 2004.

[124] V. Vogelsberg-Ragaglia, T. Schuck, J. Q. Trojanowski, and V. M. Y. Lee, "PP2A mRNA expression is quantitatively decreased in Alzheimer's disease hippocampus," Experimental Neurology, vol. 168, no. 2, pp. 402-412, 2001.

[125] M. C. Galas, P. Dourlen, S. Begard et al., "The peptidylprolyl cis/trans-isomerase Pin1 modulates stress-induced dephosphorylation of Tau in neurons: implication in a pathological mechanism related to Alzheimer disease," Journal of Biological Chemistry, vol. 281, no. 28, pp. 19296-19304, 2006.

[126] M. Hamdane, P. Dourlen, A. Bretteville et al., "Pin1 allows for differential Tau dephosphorylation in neuronal cells," Molecular and Cellular Neuroscience, vol. 32, no. 1-2, pp. 155160, 2006.

[127] X. Z. Zhou, O. Kops, A. Werner et al., "Pin1-dependent prolyl isomerization regulates dephosphorylation of Cdc25C and Tau proteins," Molecular Cell, vol. 6, no. 4, pp. 873-883, 2000.

[128] R. Sultana, D. Boyd-Kimball, H. F. Poon et al., "Oxidative modification and down-regulation of Pin1 in Alzheimer's disease hippocampus: a redox proteomics analysis," Neurobiology of Aging, vol. 27, no. 7, pp. 918-925, 2006.

[129] J. R. Thorpe, S. J. Morley, and S. L. Rulten, "Utilizing the peptidyl-prolyl cis-trans isomerase Pin1 as a probe of its phosphorylated target proteins: examples of binding to nuclear proteins in a human kidney cell line and to tau in Alzheimer's diseased brain," Journal of Histochemistry and Cytochemistry, vol. 49, no. 1, pp. 97-107, 2001.

[130] M. P. Mazanetz and P. M. Fischer, "Untangling tau hyperphosphorylation in drug design for neurodegenerative diseases," Nature Reviews Drug Discovery, vol. 6, no. 6, pp. 464479, 2007.

[131] D. C. David, S. Hauptmann, I. Scherping et al., "Proteomic and functional analyses reveal a mitochondrial dysfunction in P301L tau transgenic mice," Journal of Biological Chemistry, vol. 280, no. 25, pp. 23802-23814, 2005.

[132] V. Rhein, X. Song, A. Wiesner et al., "Amyloid- $\beta$ and tau synergistically impair the oxidative phosphorylation system in triple transgenic Alzheimer's disease mice," Proceedings of the National Academy of Sciences of the United States of America, vol. 106, no. 47, pp. 20057-20062, 2009.

[133] M. Escobar-Khondiker, M. Hollerhage, M. P. Muriel et al., "Annonacin, a natural mitochondrial complex I inhibitor, causes tau pathology in cultured neurons," Journal of Neuroscience, vol. 27, no. 29, pp. 7827-7837, 2007.

[134] K. de Vos, V. Goossens, E. Boone et al., "The 55-kDA tumor necrosis factor receptor induces clustering of mitochondria through its membrane-proximal region," Journal of Biological Chemistry, vol. 273, no. 16, pp. 9673-9680, 1998.

[135] J. J. Lemasters, A. L. Nieminen, T. Qian et al., "The mitochondrial permeability transition in cell death: a common mechanism in necrosis, apoptosis and autophagy," Biochimica et Biophysica Acta, vol. 1366, no. 1-2, pp. 177-196, 1998.

[136] K. E. Miller and M. P. Sheetz, "Axonal mitochondrial transport and potential are correlated," Journal of Cell Science, vol. 117, no. 13, pp. 2791-2804, 2004.
[137] Y. H. Hung, A. I. Bush, and R. A. Cherny, "Copper in the brain and Alzheimer's disease," Journal of Biological Inorganic Chemistry, vol. 15, no. 1, pp. 61-76, 2010.

[138] K. Jomova, D. Vondrakova, M. Lawson, and M. Valko, "Metals, oxidative stress and neurodegenerative disorders," Molecular and Cellular Biochemistry, vol. 345, no. 1-2, pp. 91104, 2010.

[139] S. Rivera-Mancia, I. Perez-Neri, C. Rios, L. Tristan-Lopez, L. Rivera-Espinosa, and S. Montes, "The transition metals copper and iron in neurodegenerative diseases," ChemicoBiological Interactions, vol. 186, no. 2, pp. 184-199, 2010.

[140] J. A. Duce, A. Tsatsanis, M. A. Cater et al., "Iron-export ferroxidase activity of $\beta$-amyloid precursor protein is inhibited by zinc in Alzheimer's disease," Cell, vol. 142, no. 6, pp. 857$867,2010$.

[141] J. Dong, C. S. Atwood, V. E. Anderson et al., "Metal binding and oxidation of amyloid- $\beta$ within isolated senile plaque cores: raman microscopic evidence," Biochemistry, vol. 42, no. 10, pp. 2768-2773, 2003.

[142] Z. Y. Mo, Y. Z. Zhu, H. L. Zhu, J. B. Fan, J. Chen, and Y. Liang, "Low micromolar zinc accelerates the fibrillization of human Tau via bridging of Cys-291 and Cys-322," Journal of Biological Chemistry, vol. 284, no. 50, pp. 34648-34657, 2009.

[143] N. Sahara, S. Maeda, M. Murayama et al., "Assembly of two distinct dimers and higher-order oligomers from full-length tau," European Journal of Neuroscience, vol. 25, no. 10, pp. 3020-3029, 2007.

[144] L. M. Sayre, G. Perry, P. L. R. Harris, Y. Liu, K. A. Schubert, and M. A. Smith, "In situ oxidative catalysis by neurofibrillary tangles and senile plaques in Alzheimer's disease: a central role for bound transition metals," Journal of Neurochemistry, vol. 74, no. 1, pp. 270-279, 2000.

[145] M. A. Smith, P. L. R. Harris, L. M. Sayre, and G. Perry, "Iron accumulation in Alzheimer disease is a source of redoxgenerated free radicals," Proceedings of the National Academy of Sciences of the United States of America, vol. 94, no. 18, pp. 9866-9868, 1997.

[146] P. LoPresti and G. W. Konat, "Hydrogen peroxide induces transient dephosphorylation of tau protein in cultured rat oligodendrocytes," Neuroscience Letters, vol. 311, no. 2, pp. 142-144, 2001.

[147] P. J. Crouch, A. R. White, and A. I. Bush, "The modulation of metal bio-availability as a therapeutic strategy for the treatment of Alzheimer's disease," FEBS Journal, vol. 274, no. 15, pp. 3775-3783, 2007.

[148] P. Sanz, "Yeast as a model system to study glucose-mediated signalling and response," Frontiers in Bioscience, vol. 12, pp. 2358-2371, 2007.

[149] F. Madeo, S. Engelhardt, E. Herker et al., "Apoptosis in yeast: a new model system with applications in cell biology and medicine," Current Genetics, vol. 41, no. 4, pp. 208-216, 2002.

[150] L. H. Hartwell, "Nobel Lecture. Yeast and cancer," Bioscience Reports, vol. 22, no. 3-4, pp. 373-394, 2002.

[151] W. H. Mager and J. Winderickx, "Yeast as a model for medical and medicinal research," Trends in Pharmacological Sciences, vol. 26, no. 5, pp. 265-273, 2005.

[152] V. Franssens, E. Boelen, J. Anandhakumar, T. Vanhelmont, S. Buttner, and J. Winderickx, "Yeast unfolds the road map toward $\alpha$-synuclein-induced cell death," Cell Death and Differentiation, vol. 17, no. 5, pp. 746-753, 2010.

[153] J. Winderickx, C. Delay, A. de Vos et al., "Protein folding diseases and neurodegeneration: lessons learned from yeast," Biochimica et Biophysica Acta, vol. 1783, no. 7, pp. 1381-1395, 2008. 
[154] G. Carmel, E. M. Mager, L. I. Binder, and J. Kuret, "The structural basis of monoclonal antibody Alz50's selectivity for Alzheimer's disease pathology," Journal of Biological Chemistry, vol. 271, no. 51, pp. 32789-32795, 1996.

[155] N. V. Uboga and J. L. Price, "Formation of diffuse and fibrillar tangles in aging and early Alzheimer's disease," Neurobiology of Aging, vol. 21, no. 1, pp. 1-10, 2000.

[156] C. L. Weaver, M. Espinoza, Y. Kress, and P. Davies, "Conformational change as one of the earliest alterations of tau in Alzheimer's disease," Neurobiology of Aging, vol. 21, no. 5, pp. 719-727, 2000.

[157] R. Nuydens, G. van den Kieboom, C. Nolten et al., "Coexpression of GSK- $3 \beta$ corrects phenotypic aberrations of dorsal root ganglion cells, cultured from adult transgenic mice overexpressing human protein tau," Neurobiology of Disease, vol. 9, no. 1, pp. 38-48, 2002.

[158] K. Spittaels, C. van den Haute, J. van Dorpe et al., "Glycogen synthase kinase- $3 \beta$ phosphorylates protein tau and rescues the axonopathy in the central nervous system of human fourrepeat tau transgenic mice," Journal of Biological Chemistry, vol. 275, no. 52, pp. 41340-41349, 2000.

[159] G. A. Jicha, C. Weaver, E. Lane et al., "cAMP-dependent protein kinase phosphorylations on Tau in Alzheimer's disease," Journal of Neuroscience, vol. 19, no. 17, pp. 74867494, 1999.

[160] Q. Zheng-Fischhofer, J. Biernat, E. M. Mandelkow, S. Illenberger, R. Godemann, and E. Mandelkow, "Sequential phosphorylation of Tau by glycogen synthase kinase- $3 \beta$ and protein kinase A at Thr212 and Ser214 generates the Alzheimerspecific epitope of antibody AT100 and requires a pairedhelical-filament-like conformation," European Journal of Biochemistry, vol. 252, no. 3, pp. 542-552, 1998.

[161] T. Kimura, T. Ono, J. Takamatsu et al., "Sequential changes of tau-site-specificphosphorylation during development of paired helical filaments," Dementia, vol. 7, no. 4, pp. 177-181, 1996.

[162] S. Kar, J. Fan, M. J. Smith, M. Goedert, and L. A. Amos, "Repeat motifs of tau bind to the insides of microtubules in the absence of taxol," EMBO Journal, vol. 22, no. 1, pp. 70-77, 2003.

[163] M. L. Gupta, C. J. Bode, G. I. Georg, and R. H. Himes, "Understanding tubulin-taxol interactions: mutations that impart Taxol binding to yeast tubulin," Proceedings of the National Academy of Sciences of the United States of America, vol. 100, no. 11, pp. 6394-6397, 2003.

[164] Y. S. H. Tan, P. A. Morcos, and J. F. Cannon, "Pho85 phosphorylates the Glc7 protein phosphatase regulator Glc8 in vivo," Journal of Biological Chemistry, vol. 278, no. 1, pp. 147-153, 2003.

[165] K. P. Lu, S. D. Hanes, and T. Hunter, "A human peptidylprolyl isomerase essential for regulation of mitosis," Nature, vol. 380, no. 6574, pp. 544-547, 1996.

[166] P. Zabrocki, K. Pellens, T. Vanhelmont et al., "Characterization of $\alpha$-synuclein aggregation and synergistic toxicity with protein tau in yeast," FEBS Journal, vol. 272, no. 6, pp. 13861400, 2005. 


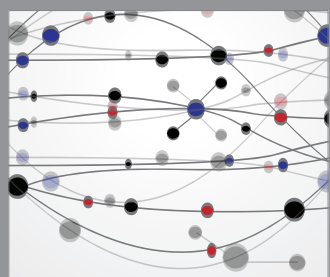

The Scientific World Journal
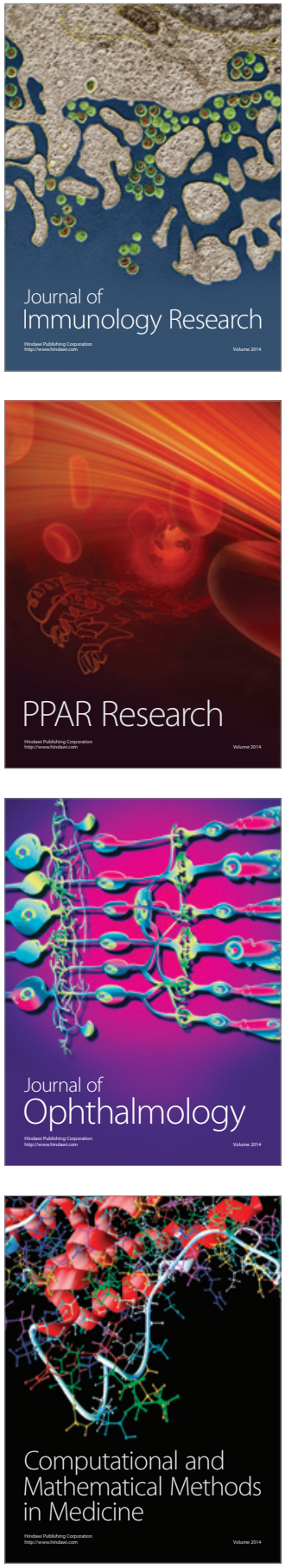

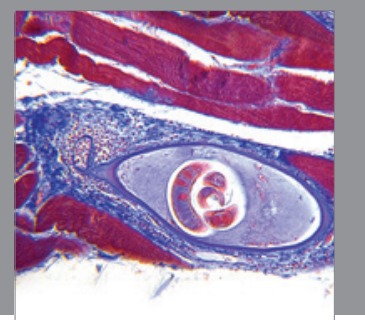

Gastroenterology

Research and Practice
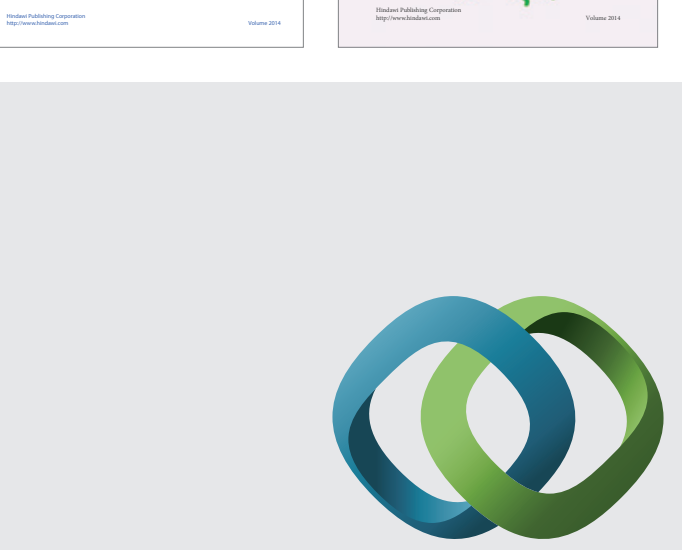

\section{Hindawi}

Submit your manuscripts at

http://www.hindawi.com
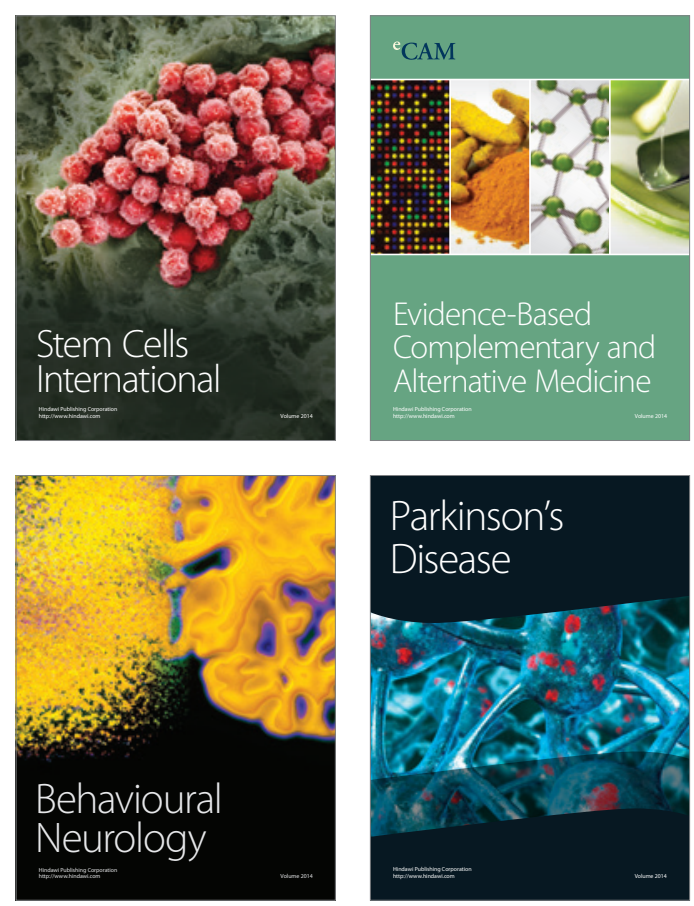

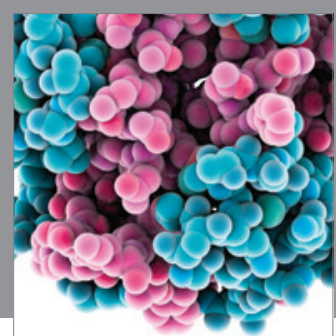

Journal of
Diabetes Research

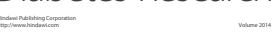

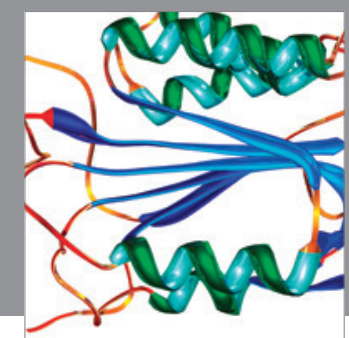

Disease Markers
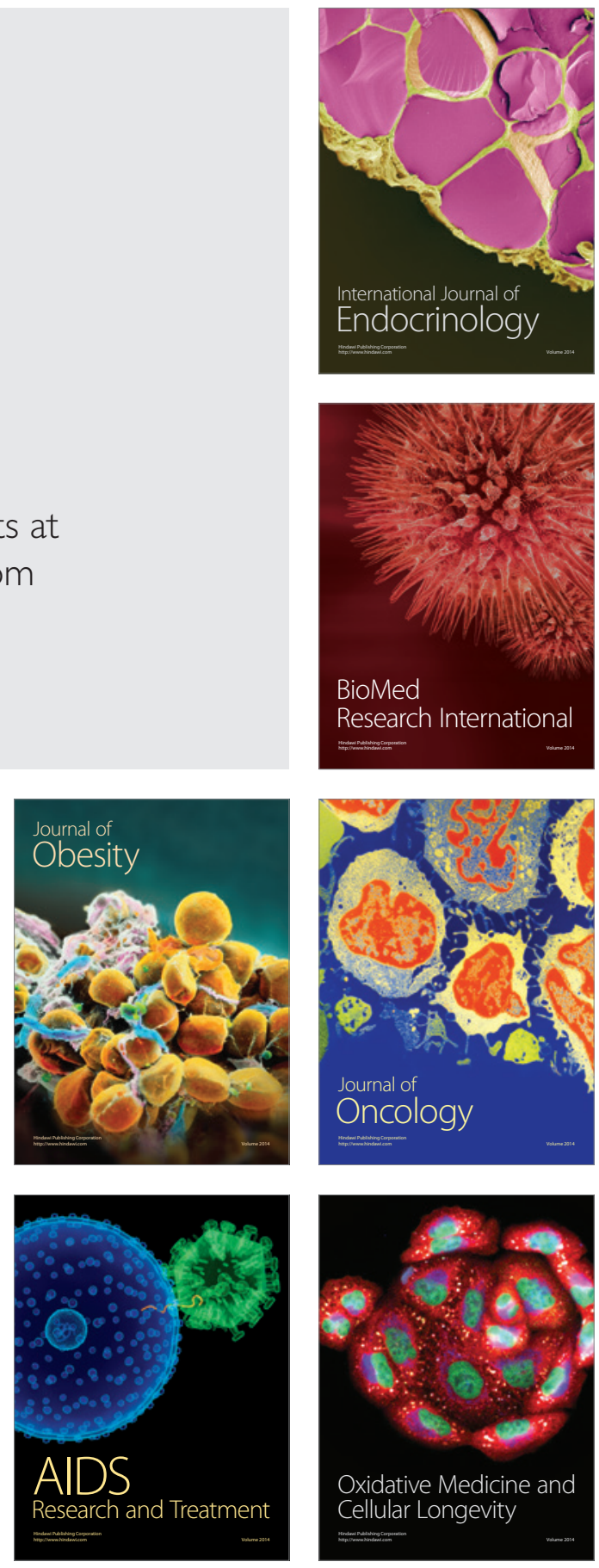